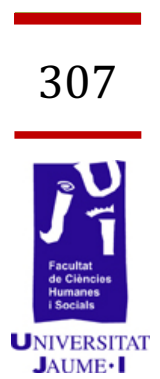

\title{
La interpretación de una obra de arte como estrategia de aprendizaje
}

Verónica Planes Vitores vplanes13@gmail.com

Paloma Palau Pellicer ppalau@uji.es 
La experiencia que presentamos corresponde a la investigación desarrollada en el ámbito de la Educación Artística y Visual en la Educación Primaria. Se trata de un proyecto experimental vinculado a las prácticas realizadas en el Colegio Público Tombatossals, ubicado en Castellón de La Plana. La propuesta viene motivada principalmente por explorar las principales causas que anulan el deseo de expresión del alumnado y con ello, su imaginación. En segundo lugar, nos parece importante fomentar que el alumnado tenga un conocimiento del patrimonio que le rodea. Por ello, nuestra investigación versará sobre la interpretación de "La rendición de Breda" (1534) de Diego Velázquez que elaborará el alumnado de tercer curso de primaria. Para llevar a cabo los objetivos propuestos anteriormente, se han empleado dos enfoques metodológicos: la observación y la experimentación. A modo de conclusión, se reflexiona sobre la importancia que tiene la historia del arte en la escuela, además de cómo la interpretación de una obra de arte es un vehículo para desarrollar competencias y contenidos relacionados con las artes visuales.

Palabras clave: Diego Velázquez, historia del arte, Educación Artística y Visual, Educación Primaria, creatividad.

\section{Introducción}

Esta investigación corresponde al Trabajo Fin de Grado en Maestra de Educación Primaria. La experiencia se desarrolla dentro del área de Didáctica de la Expresión Plástica, tutorizado por la Dra. Paloma Palau Pellicer y es un proyecto experimental vinculado a las prácticas realizadas en el Colegio Público Tombatossals, ubicado en Castellón de La Plana. Tomamos por ello, como punto de partida, el siguiente objetivo "mantener una actitud de búsqueda personal o colectiva, articulando la percepción, la imaginación, la indagación, la sensibilidad junto con la reflexión a la hora de realizar y disfrutar de diferentes producciones artísticas" incluido en el Decreto 111/2007, para la enseñanza de la Educación Artística. Nuestra investigación trata sobre la interpretación de una obra artística con el alumnado del tercer curso de Primaria del CEIP Tombatossals. Concretamente "La Rendición de Breda" de Diego Velázquez, cuya elección justificaremos más adelante con detalle, así como la elección del autor. Nuestra finalidad, es conseguir que el alumnado tenga un conocimiento del patrimonio que le rodea. Para ello, es importante comenzar educando el sentido de la observación, a través del análisis de los elementos que les rodean y de las imágenes que se proyectan en el aula.

Por último, el centro en el que he realizado la experiencia ha estado abierto a la propuesta tanto el alumnado como el equipo docente del centro. De hecho, en este centro, la asignatura de Plástica solo tiene una sesión semanal de 50 minutos y, gracias a Elena Cabedo, mi tutora de 
prácticas, durante la fase de intervención del proyecto hemos utilizado dos sesiones para desarrollar la tarea.

EI C.E.I.P. Tombatossals se encuentra situado al norte de la ciudad, en el PAU Lledó, zona relativamente nueva de viviendas unifamiliares y bloques de edificios bajos. Por lo que respecta al alumnado que ha participado en esta experiencia es el de 30 Primaria, un grupo integrado por 23 alumnos/as, más una alumna de aula de Comunicación y Lenguaje (CYL) de tipo A, que hace algunas integraciones en el aula. En general, es un curso con muy buena actitud y con alumnado de gran potencial, aunque hay 2 alumnos que asisten al aula de Pedagogía Terapéutica (PT) y 1 alumno necesita atención o refuerzo.

Todos los años el C.E.I.P. Tombatossals organiza una fiesta para celebrar el final del curso académico. Para ello, a principio de curso, durante la celebración del claustro escolar se debate sobre la temática de la fiesta. Este año se conmemora el IV Centenario de la muerte del pintor "El Greco» y que mejor homenaje que realizar un proyecto sobre pintores. Establecida la temática general en el centro escolar, solo quedaba decidir quiénes iban a ser los pintores a estudiar por ciclo educativo, en cada trimestre. Los pintores Manolo Dos, Diego Velázquez y Vicente Castell fueron los seleccionados para el segundo ciclo educativo. Esta elección se justifica porque pensaron en escoger pintores que fuesen locales así como con repercusión internacional. El inicio de las prácticas en el centro escolar coincide con el inicio del segundo trimestre por lo que el pintor a estudiar era Diego Velázquez. Así pues, únicamente quedaba escoger el cuadro para realizar la interpretación. En un principio, decidimos que el alumnado eligiese la obra a partir de una selección de cuadros del pintor en cuestión. En principio el procedimiento con el que ellos determinarían la obra iba a ser mediante una asamblea pero al llevarlo a la práctica fue desestimado. Ya que el criterio del alumnado no estaba fundamentado en criterios de composición, forma, color, significado del cuadro, sino por otros factores alejados de nuestro objetivo. Y precisamente esto es lo que queríamos evitar. Además, de fundamentar nuestra elección a partir de lo anteriormente expuesto, debíamos escoger un cuadro en el que apareciese una multitud de personajes, ya que el grupo al completo debía representarlo a final de curso. Velázquez fue un pintor de la realeza, por tanto, desestimamos los retratos reales por representar a un único personaje y los de temática mitológica como "Las Hilanderas" o "La Fragua de Vulcano". Por otro lado, aunque en el cuadro de "Las Meninas" aparecen más personajes y tiene una gran relevancia por el dominio de la perspectiva, no fue seleccionado. Puesto que ha sido interpretado por multitud de pintores de diversas épocas, como veremos más adelante, por lo que nos serviría para realizar la presentación de la parte teórica.

Finalmente, decidimos que el cuadro, objeto de estudio, fuese "La Rendición de Breda", también conocido como "Las Lanzas" (Figura 1). Aunque este cuadro se enmarca dentro de la temática bélica, Velázquez resuelve el conflicto de una manera eficaz y elegante. En esta escena "se insiste en la clemencia y la magnanimidad», si bien, observamos como la 
victoria es resaltada en la superioridad de las lanzas españolas sobre las picas holandesas. Asimismo, es otra de las obras cumbres del pintor en el que transmite de manera muy efectiva la versión oficial de un hecho bélico. En este cuadro se puede observar una composición estable con dos figuras centrales, además del paisaje luminoso y brumoso de los campos de combate y humos con los cielos del norte de Europa.
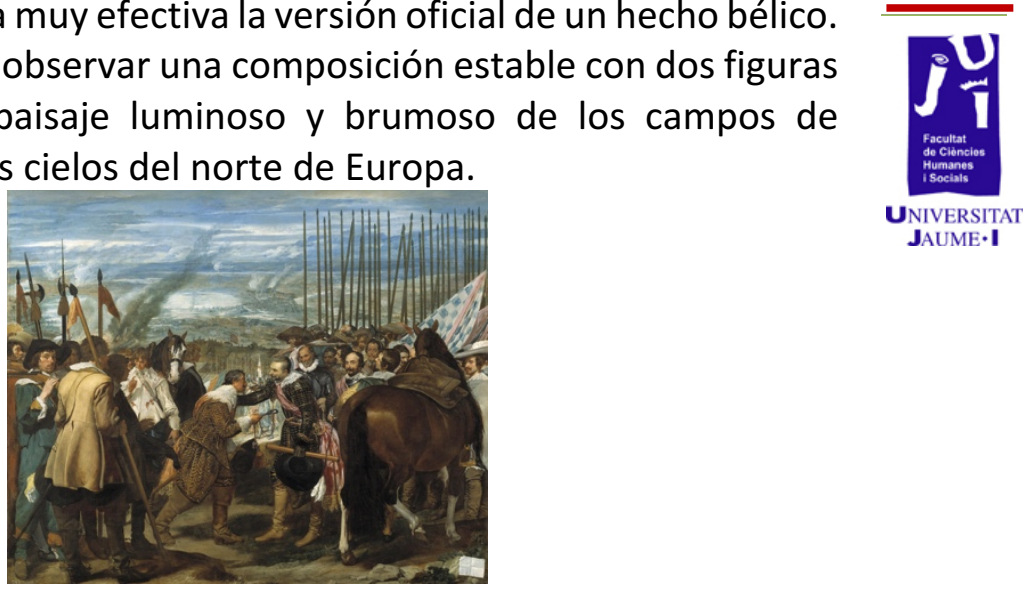

Figura 1. "La Rendición de Breda” Diego Velázquez, 1634.

\section{Objetivos}

La Educación Artística es una de las áreas que está integrada en el Decreto 111/2007, de 20 de julio, del Consell, por el que se establece el currículo de la Educación Primaria en la Comunitat Valenciana. Esta área se subdivide en dos apartados: Plástica y Música. Y, aunque la educación artística tiene el mismo tratamiento en el citado Decreto, no ocurre lo mismo en la praxis. Y esto se debe a que la asignatura de Plástica comparte sus horas con la asignatura de Música, por lo que muchos centros ven limitada su docencia a una sesión de 50 minutos de un total de las 25 horas que tienen semanalmente. Por lo que se refiere a los contenidos, estos dos lenguajes, tanto el plástico y visual como el musical se articulan en el currículum en dos vertientes, percepción y expresión. La percepción «se refiere a la observación de los elementos plásticos y a la audición musical. La observación debe centrarse en la interpretación, indagación y análisis del entorno natural y de las creaciones humanas» (Decreto 111/2007). Por ello, nuestra investigación va asociada a la interpretación de una obra de arte, porque nuestro alumnado debe aprender a observar y percibir para alcanzarlos, debe saber interpretar. Además, como dice el Decreto $111 / 2007$, «es necesario estimular la imaginación en una dimensión en la cual el arte ofrece nuevas posibilidades de organización de la inteligencia y para facilitar su correcto uso e incrementar su capacidad de concentración y favorecer la resolución de problemas de cualquier área». Éste es otro de los motivos por los que decidimos escoger una obra de arte, no solo para estimular la imaginación del alumnado, sino para que no pierda su capacidad de concentración y sobre todo, para que pueda enfrentarse de manera individual a los problemas que se le vayan planteando. Esto último tiene una estrecha relación con los contenidos que se programan en la asignatura de artes visuales. 
Una de las principales causas que anulan el deseo de expresión del alumnado y con ello, su imaginación y capacidad para resolver problemas es copiar y colorear imágenes. Compartimos con la profesora María Dolores Medina que no es adecuado «acostumbrarlos a seguir modelos realizados por los adultos, copiar, alcanzar patrones, colorear imágenes ya creadas, o darles pautas de todo lo que tienen que hacer en cada momento» (Medina, 2006) pues sobre todo, merma su interés por observar. Y esto está ocurriendo en las aulas de Primaria, las profesoras Luisa Martínez y Charo Gutiérrez, de la Universidad de Málaga advierten que «se sienten cómodos copiando y coloreando dibujos, pero a medida que lo hacen también son conscientes de que nunca podrían crear uno igual sin copiarlo y ello provoca inhibición con respecto a la creación libre» (Martínez y Gutiérrez, 2011). Se les proporcionan imágenes de temáticas diferentes, muchas veces, siguiendo el calendario con los acontecimientos más señalados como el Día de la Paz, las fiestas de la Magdalena o Pascua. Es, en estas ocasiones, cuando la expresión plástica queda reducida a una acción simple y repetitiva en la que lo único que tienen que hacer es colorear. De este modo, no tienen ningún problema creativo que resolver pues todo les viene dado. Sus preguntas se reducen básicamente a qué tipo de material pueden utilizar y de qué colores pueden pintar los elementos que hay en el papel. Por tanto, no se les ofrece la posibilidad de enfrentarse a problemas de tipo estético o creativo derivados de propuestas abiertas. Con este tipo de prácticas no se les estimula para observar lo que tienen en su entorno externo más inmediato, ni para imaginar alternativas con diferentes soluciones. Además, este tipo de ejercicios carecen de valor educativo y artístico, ya que el niño/a no desarrolla ninguna habilidad para expresarse con el lenguaje plástico. Esta situación se agrava cuando llegan a los $8-9$ años de edad, ya que su interés por expresarse se mitiga. Por tanto, uno de los retos más importantes del docente será el de estimular al niño/a de la gran importancia y valor que tiene su expresión, sea cual sea, tal como propone Medina. Es importante que a través de la percepción y expresión plástica, el alumnado analice los elementos de la realidad que le rodea y la represente visualmente, ya que si no lo consigue se va frustrando y no desarrolla las capacidades para expresarse gráficamente y formarse como individuo.

De esta manera, educar a través del arte favorece las capacidades mentales y conductuales del niño/a, es decir, se estimulan su expresión libre e individual y todo su potencial creativo. Tal y como propone Howard Gardner «la educación artística ha continuado siendo considerada un vehículo para fomentar la autoexpresión, la imaginación, la creatividad y el conocimiento de la propia vida afectiva - no como un tema escolar, no como un oficio que ha de dominarse» (Gardner, 1994). Educamos para conseguir un pensamiento divergente. La mayoría de las áreas educativas favorecen el pensamiento convergente, es decir, "solo promueven la formación de una memoria episódica que alberga contenidos aislados para resolver con éxito los problemas que le surgen en el aula» (Martínez y Gutiérrez, 2011). Una de las aportaciones de educar en y con las artes 
visuales es el desarrollo de un espíritu crítico con el que ser capaces de decidir y tomar sus propias decisiones. Además, esta disciplina, ofrece las herramientas no sólo para resolver problemas dentro del aula sino fuera de ella. Como docentes, no podemos obviar que existe una evolución gráfico-plástica y en las aulas debemos fomentar este proceso en pro de las necesidades educativas del niño/a. Sin embargo, como ya hemos comentado anteriormente, esto se tiene en cuenta en contadas ocasiones en las aulas de Primaria. A pesar de que, el Decreto 111/2007 establece el objetivo siguiente: «Aplicar los conocimientos artísticos en la observación y el análisis de situaciones y objetos de la realidad cotidiana y de diferentes manifestaciones del mundo del arte y la cultura para comprenderlos mejor y formar un gusto propio» como uno de sus objetivos en la enseñanza artística para desarrollar esta capacidad.

$Y$ es que las diferentes manifestaciones artísticas tienen una presencia constante en la vida de las personas (Decreto 111/2007) por lo que esta área contribuye directamente al desarrollo de una serie de competencias básicas. Citaremos los puntos más importantes de cada competencia:

- Social y ciudadana. "La interpretación y la creación suponen, en muchas ocasiones, un trabajo en equipo".

- Conocimiento e interacción con el mundo físico. "Apreciar el entorno a través del trabajo perceptivo con sonidos, formas, colores, líneas, texturas, luz o movimiento presentes en los espacios naturales y en las obras y realizaciones humanas".

- Aprender a aprender. "Reflexión sobre los procesos en la manipulación de objetos y la experimentación con técnicas y materiales".

- Comunicación lingüística. "Riqueza de los intercambios comunicativos que se generan (...) y del vocabulario específico que el área aporta".

- Tratamiento de la información y la competencia digital. "Uso de la tecnología como herramienta para mostrar procesos relacionados con las artes visuales y para acercar al alumnado a la creación de producciones artísticas".

Por otro lado, los objetivos generales que aparecen en el área de la Educación Artística, incluidos en el Decreto 111/2007 y que van a contribuir en el desarrollo de nuestra experimentación son los siguientes:

- Desarrollar la capacidad de observación y la sensibilidad para apreciar las cualidades estéticas y visuales.

- Aprender a expresar y comunicar con autonomía e iniciativa emociones y vivencias a través de los procesos propios de la creación artística en su dimensión plástica.

- Aplicar los conocimientos artísticos en la observación y el análisis de situaciones y objetos de la realidad cotidiana y de diferentes manifestaciones del mundo del arte y la cultura para comprenderlos mejor y formar un gusto propio.

- Mantener una actitud de búsqueda personal o colectiva, articulando la percepción, la imaginación, la indagación, la 
sensibilidad junto con la reflexión a la hora de realizar y disfrutar de producciones artísticas.

Así pues, entre los objetivos generales de la educación primaria hay uno que pretende contribuir a desarrollar en el alumnado actitudes encaminadas a una "valoración y conservación de los restos históricoartísticos presentes en el medio como fuente de información sobre la historia de nuestros antepasados» (MEC 1992). De este modo, es importante que conozcan el patrimonio pues gracias a ello, como apuntábamos anteriormente, se generan actitudes críticas hacia nuestro patrimonio que promueven cambios de actitudes y enriquecimiento personal (Pérez, 2012).

Por último, nos apoyaremos en Roser Juanola para contestar a la pregunta ¿por qué es bueno conocer obras de arte? Esta autora establece cinco puntos en los que defiende el conocimiento del patrimonio ya que favorece:

- La percepción y expresión de emociones propias y opiniones.

- La construcción de un conocimiento interdisciplinar: histórico, social, natural y cultural.

- El desarrollo de estrategias y habilidades de investigación a partir de la observación, experimentación y el contacto directo con el medio.

- La interpretación de significados.

- La toma de decisiones para la elaboración de propuestas.

\section{Material y metodología}

La importancia de la metodología en un proyecto de investigación se debe a que "los métodos hacen posible que los niños alcancen los objetivos» (Torres y Juanola, 1998). Durante la segunda mitad del siglo XX, se desarrollaron dos tendencias sobre el modo de enfocar la enseñanza del dibujo en los centros de Primaria. El profesor Ricardo Marín-Viadel resalta:

Por un lado, las tendencias creativas y naturales, que confían plenamente en el propio proceso de desarrollo y maduración espontánea, y que propugnan una concentración e intensificación en los modos propios que tiene cada niño o niña de resolver y recrearse en sus estrategias gráficas. Por otro lado, las tendencias que ponen el énfasis en la conexión de los dibujos que hacen los niños y niñas con las grandes obras de arte. (Marín-Viadel, 2003)

Estas dos tendencias serían las deseables para que se desarrollaran dentro de las aulas de Primaria, pero, como hemos explicado en el apartado anterior, está situación no es habitual. Hemos intentado llevar a cabo estas dos orientaciones que nos plantea Marín-Viadel para conseguir que se dieran una serie de contenidos y se alcanzasen unos objetivos concretos. La primera orientación debe consistir en la motivación, incentivación y comprensión en profundidad de las características de las obras gráficas que el alumnado realiza por sí mismo, tal como proponen Lowenfeld y Freinet. Por ello, se debe crear un clima agradable, donde el 
alumnado trabaje bajo su autoexpresión creativa y no bajo la imposición. Por otro lado, como apunta Marín-Viadel «el matrimonio Wilson y Al Hurwitz, afirmaba que la fuente principal de estudio para aprender a dibujar en la escuela son las grandes obras maestras del dibujo porque han elaborado y descubierto un gran número de ideas y soluciones visuales para resolver de forma satisfactoria los problemas gráficos con los que se debe enfrentar todo dibujo, y también los que se propone hacer el alumnado en la escuela primaria» (Marín-Viadel, 2003). Así pues, ya tenemos los dos elementos que van a formar parte del método de enseñanza en este proyecto: la autoexpresión y una obra de arte. Según el matrimonio Wilson y Al Hurwitz, su enseñanza combinaba diferentes tipos de dibujo y conceptos gráficos dentro del programa escolar, entre los que destacamos la observación y el tema o asunto que desarrolla el dibujo y los símbolos que aparecen en él, respectivamente. Además, tres de las cuatro ideas a partir de los cuales desarrollan su enfoque de enseñanza del dibujo son:

[...] el mejor método de enseñanza del dibujo en la escuela es el de dibujar recreando las grandes obras de arte, el mejor método para apreciar y comprender una obra de arte es recrearla dibujando y el mejor método para desarrollar la individualidad, la originalidad y la capacidad inventiva del alumnado es el conocimiento, estudio, recreación y conocimiento profundo de las mejores obras de arte. (Marín-Viadel, 2003)

De esta forma, en esta práctica educativa, combinamos en las distintas fases del proyecto dos enfoques metodológicos: la observación y la experimentación, desarrollados con prácticas pautadas y fomentando la autoexpresión.

La primera fase es la parte teórica del proyecto y en la que el alumnado conoce quién es el pintor Diego Velázquez. Para ello, se les mostrará, con una proyección, los contenidos a desarrollar a partir de la biografía del autor, su obra y el concepto de interpretación. En la primera se explicará su vida y trayectoria mostrando los cuadros más relevantes del pintor. En la segunda, explicaremos qué es interpretar con ejemplos de las diferentes interpretaciones que se han hecho a lo largo de la historia del arte de "Las Meninas" de Velázquez por reconocidos autores como Goya, Picasso que realizó 58 interpretaciones del citado cuadro en 1957, Dalí, Ramón Gaya, Equipo Crónica, Richard Hamilton, Cristóbal Toral y Antonio Mingote entre otros muchos.

En las figuras 2 y 3 vemos varias interpretaciones del cuadro "Las Meninas", obra que ha tenido una gran influencia en los pintores posteriores. Cada uno de ellos ha aportado su propia seña de identidad, realizando su propia versión y reflejando su admiración por esta obra. Estas interpretaciones están realizadas por dos pintores también reconocidos. En la figura 2 podemos ver dos cuadros de Dalí. Uno de ellos es "El número secreto de Velázquez", una monocromía con números que servirá de inspiración a varios de nuestros alumnos, como veremos en el siguiente apartado. En la figura 3 se muestran dos de las 58 interpretaciones que realizó Picasso de "Las Meninas". En esta serie de cuadros, el pintor estudia 
claves de color, composiciones cubistas, elimina personajes o incluso introduce elementos ajenos a la obra de Velázquez.

DALÍ

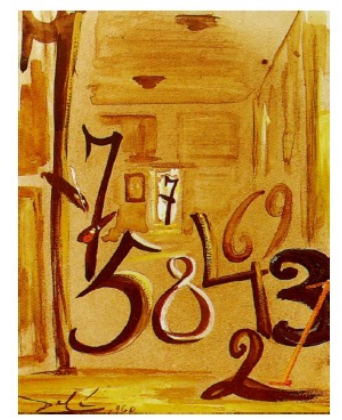

Figura 2. Interpretaciones de Dalí
PICASSO - 1957

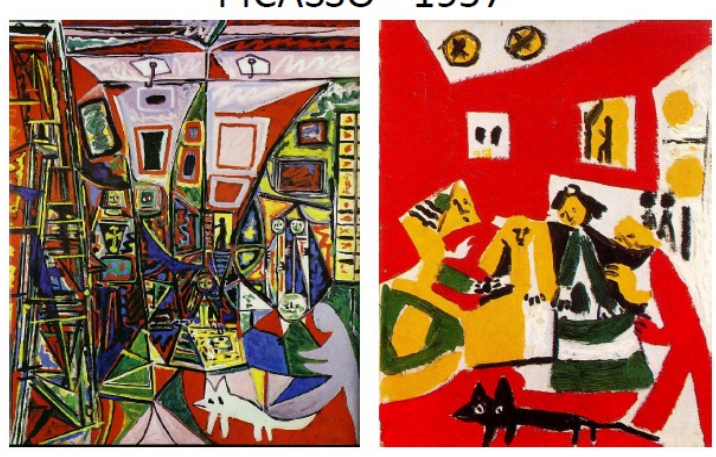

Figura 3. Interpretaciones de Picasso

Los contenidos que se proponen en esta primera fase son procedimentales, conceptuales y contextuales. En lo que respecta al primero, se promoverá la percepción que se llevará a cabo a través de la observación y análisis visual de diferentes obras de arte del pintor. En los conceptuales, básicamente explicaremos las diferentes técnicas de dibujo que utilizó Velázquez en su trayectoria, como la técnica del claroscuro y el realismo, además de diferentes aspectos formales, como el color y la proporción. Por lo que se refiere a los contenidos, están relacionados con el contexto, puesto que es fundamental mencionar que la época a la que se adscribe el pintor es el Barroco - pintura que se desarrolla en el siglo XVII- y describir esta época para que puedan comprender la obra de Velázquez. La pintura barroca transmite el dramatismo de una época marcada por una profunda crisis económica y social, representada de forma naturalista utilizando la técnica del claroscuro: fondos muy oscuros con las personas y objetos muy iluminados con un foco muy potente. Velázquez amplió horizontes y destacó posteriormente por su realismo. Fue pintor de la corte del rey Felipe IV, por lo que pintó a toda la familia real, y plasmó acontecimientos relevantes para la corte, como fue "La Rendición de Breda". Por lo tanto, el objetivo principal de esta primera fase es la observación, ya que ésta «permite el análisis de la realidad percibida y la de las imágenes» (Torres y Juanola, 1998). Mientras se proyectan las dos presentaciones se les irá haciendo preguntas para comprobar que el alumnado sigue la explicación y comprende los conceptos. Entre las preguntas que se plantearon destacamos las que hacen referencia a las técnicas que utilizó el pintor. La primera fue la técnica del claroscuro y un claro ejemplo de esta técnica es el cuadro "La vieja friendo huevos" (Figura 4)

Preguntas como: ¿de qué color es el fondo?, ¿vemos la cesta donde está apoyada?, y el niño, ¿tiene cuerpo?, ¿qué partes de su cuerpo 
podemos apreciar con exactitud? En cambio, en la segunda etapa del pintor, ya vemos como resalta el color, el desnudo y la perspectiva. En la "Fragua de Vulcano" se les preguntará: ¿qué colores aparecen?, ¿cómo son esos colores, vivos o apagados? En el cuadro de "El Triunfo de Baco": ¿Llevan ropa?, ¿cómo es?, ¿tienen alguna parte de su cuerpo desnudo? En el cuadro de "Las Lanzas" las preguntas girarán en torno a la perspectiva: ¿os fijáis en el humo del fondo?, ¿y las montañas?, ¿cómo las representa?, ¿qué tamaño tienen?

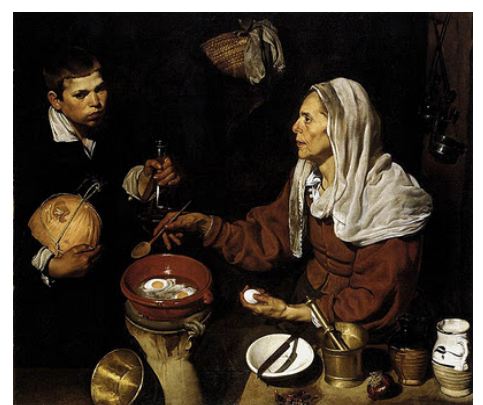

Figura 4. "Vieja friendo huevos" Diego Velázquez, 1618.

La segunda fase es la experimental, es decir, la parte práctica del proyecto en la que los niños y niñas realizarán su interpretación. Esta fase se subdivide a su vez en cuatro subapartados: observación de la obra pictórica objeto de estudio y posterior debate con el alumnado; análisis plástico, es decir, análisis de los aspectos formales de la pintura; actividad plástica, es decir, la interpretación por parte del alumnado y por último, reflexión del trabajo final, realizando una puesta en común en el aula. En esta fase conectamos con una de las tendencias que hemos citado anteriormente y en la que se establece una conexión de los dibujos que hacen los niños y niñas con las obras de arte.

En primer lugar, se les proyectará el cuadro de "Las lanzas". El alumnado observará el cuadro y contestará una serie de preguntas con el fin de comprobar que está comprendiendo la imagen que está viendo. ¿Qué ven?, ¿qué representa?, ¿qué elementos aparecen en la obra? Se establecerá un diálogo entre los niños y niñas y el docente con la finalidad de apreciar y comprender una obra de arte, remarcamos que esto es algo a lo que no suelen estar acostumbrados. Una vez alcanzado este primer apartado, procederemos al análisis plástico de la obra.

Ya sabemos qué elementos intervienen en la obra, por lo tanto, vamos a comprobar cómo Velázquez los resuelve en su pintura, es decir, ¿qué colores utiliza?, ¿qué proporciones utiliza?, ¿̇es un dibujo realista? y, ¿ha tenido algún problema gráfico el autor y lo ha resuelto de alguna forma? Tenemos que ser conscientes que estos dos apartados suponen una aproximación, ya que es la primera vez que se enfrentan a una obra de arte y muchos de ellos no tienen unos conocimientos previos o vocabulario específico. El tercer apartado después de las pautas teóricas y tras haber realizado una puesta en común, corresponde a la puesta en práctica del alumnado que pasará a la fase de intervención.

Durante la fase de intervención (Imagen 1), el docente tan solo realizará el papel de guía, sin dar ningún tipo de pautas. No responderá a 
preguntas relacionadas con problemas gráficos o utilización de materiales artísticos. Lo que pretendemos con este tipo de intervención es que sea el propio alumnado el que se enfrente a sus propios problemas y sea capaz de resolverlos de manera autónoma. Del mismo modo que ocurre en el proceso creativo, y por supuesto también a los pintores como Velázquez. Así pues nuestro objetivo era que el alumnado realizara su propio dibujo «aplicando las ideas gráficas que ha aprendido a partir de la obra de arte que se ha estudiado» (Marín-Viadel, 2003) En esta fase se promueve la autoexpresión individual de cada uno/a para que pueda desarrollar un pensamiento divergente, es decir, creativo, donde aplique sus estrategias gráficas y resuelva los problemas que le van surgiendo de manera autónoma.

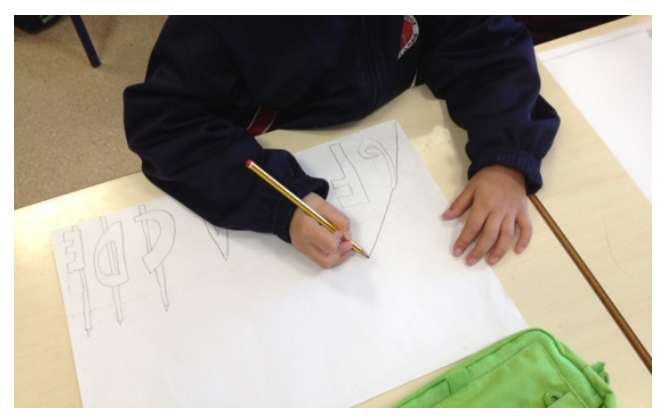

Imagen 1. Fase de intervención.

La última fase es la reflexión. En esta parte se lleva a cabo una puesta en común de las soluciones que han propuesto para elaborar su dibujo y de este modo, tienen un conocimiento de lo que ha elaborado el resto.

Respecto al alumnado, esta práctica educativa la han realizado 23 alumnos/as de tercer curso de primaria, en concreto, 12 niñas y 11 niños. Todos los participantes tienen 8 años de edad, excepto dos alumnas una que había cumplido recientemente los 9 años y otra que cuenta ya con 10 años. El grupo destaca académicamente y proviene de familias de clase media trabajadora y de clase alta. En cuanto a las necesidades educativas especiales en el aula, nos encontramos con una alumna (10 años) que requiere una Adaptación Curricular Individualizada $(\mathrm{ACl})$. Además de un alumno de 8 años diagnosticado como Asperger pero todavía no tiene ni dictamen ni tipo de $\mathrm{ACl}$ previsto.

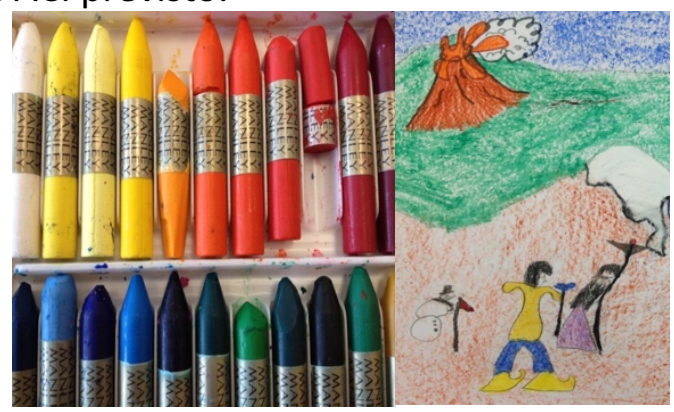

Imagen 2. Ceras y dibujo. Fotoensayo compuesto por dos fotografías de la autora. 
Es importante destacar que durante las sesiones correspondientes a la fase teórica (Tabla 1), los niños/as no han necesitado ningún tipo de material. Tan solo un ordenador y una pizarra digital con la que se han proyectado las dos presentaciones sobre el pintor y la interpretación. El alumnado ha estado atento, y ha participado activamente realizando comentarios muy estimulantes. En la fase práctica (Tabla 1), sin embargo, hemos necesitado material adecuado. En primer lugar papel blanco de 80 gramos y de formato A3. Hemos considerado más apropiado proporcionarles un papel de gran formato puesto que, por un lado, tienen más espacio para llevar a cabo un ejercicio de autoexpresión y por otro, el cambio de formato resulta inspirador ya que habitualmente trabajan en A4. Para poder elaborar el dibujo utilizaron lápiz, goma, lápices de madera, ceras de colores, ceras blandas, rotuladores y regla. Lo único que se les explicó es que podían utilizar cualquier tipo de material gráfico, que no se les iba a marcar ningún tipo de directriz, y que eran libres de elaborar su dibujo de la manera que a ellos les resultase más gratificante. Dibujaron todos con lápiz y una vez finalizados, los colorearon. Excepto una niña que realizó su dibujo únicamente con el lápiz, difuminando las partes que más le interesaban.

\begin{tabular}{|l|l|l|l|}
\hline \multicolumn{3}{|c|}{ Temporalización } \\
\hline $\begin{array}{l}\text { Fase } \\
\text { teórica }\end{array}$ & $\begin{array}{l}\text { Sesión 1: Vida y obra de } \\
\text { Velázquez. }\end{array}$ & $\begin{array}{l}\text { Sesión 2: Qué es interpretar. Ejemplo de } \\
\text { “Las Meninas”. }\end{array}$ \\
\hline $\begin{array}{l}\text { Fase } \\
\text { práctica }\end{array}$ & $\begin{array}{l}\text { Sesión 3: Observación y } \\
\text { análisis plástico del cuadro. } \\
\text { Inicio de la actividad plástica. }\end{array}$ & $\begin{array}{l}\text { Sesión 4: Actividad } \\
\text { plástica. }\end{array}$ & $\begin{array}{l}\text { Sesión 5: } \\
\begin{array}{l}\text { Reflexión y } \\
\text { pase de } \\
\text { cuestionario. }\end{array}\end{array}$ \\
\hline
\end{tabular}

Tabla 1. Fases de la investigación planificadas por sesiones.

La recogida de datos se llevó a cabo a través de fotografías y dibujos. Estos dos instrumentos son específicos de las artes visuales y gracias a ellos se ha podido extraer información relevante del proceso y los resultados. El procedimiento fue el siguiente, se tomaron diversas fotografías que se muestran a lo largo del presente trabajo y en los anexos, así como los dibujos realizados por el alumnado de 3 o de Primaria. Además de los documentos gráficos, también realizaron un cuestionario, en el que contestaban una serie de preguntas sobre su interpretación, el material que habían utilizado y su explicación de los diversos elementos que aparecen en el cuadro de Velázquez.

\section{Resultados}

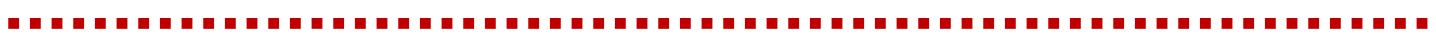

La clasificación de la evolución de los dibujos infantiles se realizó a finales del siglo XIX, en concreto, en 1885 y 1896. Son muchos los autores que lanzaron sus propuestas, como James Sully, Herman Lukens, Georg Kerschenteiner y Rouma. Ya en los años veinte y cincuenta del siglo XX, se 
produjo un boom en los estudios evolutivos sobre el dibujo infantil. Autores como C. Burt, Henri Luquet y Viktor Lowenfeld realizaron una clasificación sobre el desarrollo gráfico de los niños y niñas. Nosotros vamos a tomar como referencia a este último autor, ya que realizó una de los estudios evolutivos del grafismo infantil más importantes. Viktor Lowenfeld enunció seis etapas en el desarrollo del dibujo espontáneo infantil. La primera etapa es la del garabateo (2-4 años de edad) asociada a los movimientos motrices; la segunda etapa es la preesquemática (4-7 años), en la que comienza su descubrimiento de la relación de la representación. La tercera es la esquemática (7-9 años) en ella, el individuo descubre "el esquema" para representar una figura o elemento. De 9 a 11 años, se ubica la cuarta etapa, principio de realismo, que se aleja del esquema y las líneas geométricas. Por último, las dos etapas son la seudorrealista (11-13 años) y la decisión (13-17 años). En ellas desarrollan una conciencia crítica sobre sus dibujos.

De esta manera y siguiendo la clasificación de Lowenfeld, nuestro alumnado pertenece a la tercera etapa en el desarrollo del dibujo espontáneo. Esta etapa es la denominada esquemática y discurre entre los siete y los nueve años de edad. Lowenfeld sostiene que gracias a la actividad gráfica que ha desarrollado el niño/a durante las etapas anteriores a su desarrollo intelectual y emocional, y a sus experiencias educativas, cada persona individualmente llega a elaborar un modelo o "esquema" gráfico para cada concepto: figura humana, casa, árbol, pájaro, etc. (Marín-Viadel, 2003) Pero este "esquema" gráfico va sufriendo diversas modificaciones y transformaciones en función de lo que quieran elaborar. Y esto lo conseguirán a través de estrategias, tales como, la exageración de las partes que consideran más importantes; la supresión de partes que no tienen importancia en una escena; y la modificación de las formas cuando representan situaciones relevantes. Además en esta etapa, la "línea base" es el esquema fundamental de representación del espacio en los dibujos. También es, en esta etapa, cuando se produce la relación entre el color y el objeto, es decir, la identificación cromática de cada objeto con su color propio: el sol amarillo, las montañas marrones, etc.A continuación se muestran tres gráficos con datos cuantitativos a través de tres gráficos circulares con los elementos que han dibujado en su interpretación. El primer gráfico representa los elementos paisajísticos tales como montañas, nubes, sol, luna, volcán y río (Gráfico 1). 


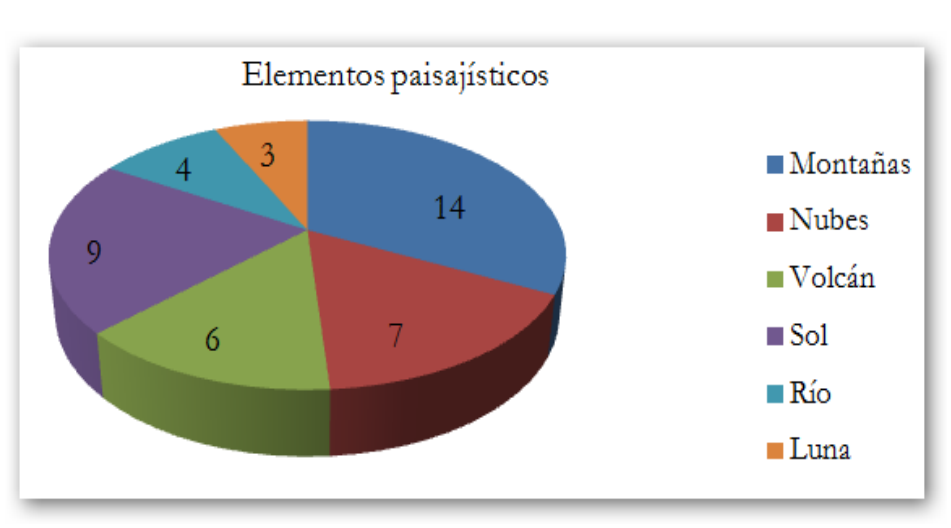

Gráfico 1. Elementos paisajísticos.

El segundo gráfico (Gráfico 2) refleja los elementos inanimados, como son las lanzas, la llave, las banderas, las casas, el folio (firma de Velázquez), elementos añadidos fuera de contexto y los cohetes. $Y$ el tercer gráfico (Gráfico 3) reproduce los seres vivos que aparecen en las interpretaciones. Hemos querido representar tres gráficos para, en primer lugar, agrupar elementos que son comunes y en segundo lugar, reflejarlo visualmente.

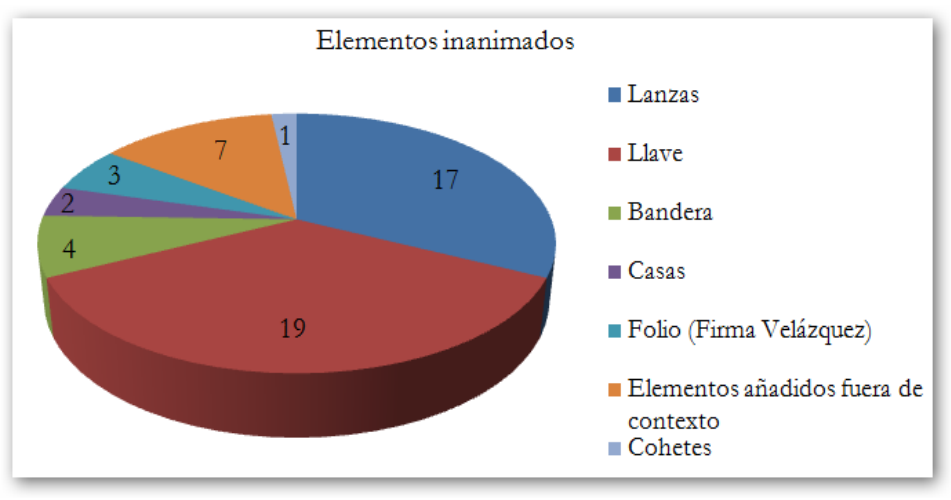

Gráfico 2. Elementos inanimados

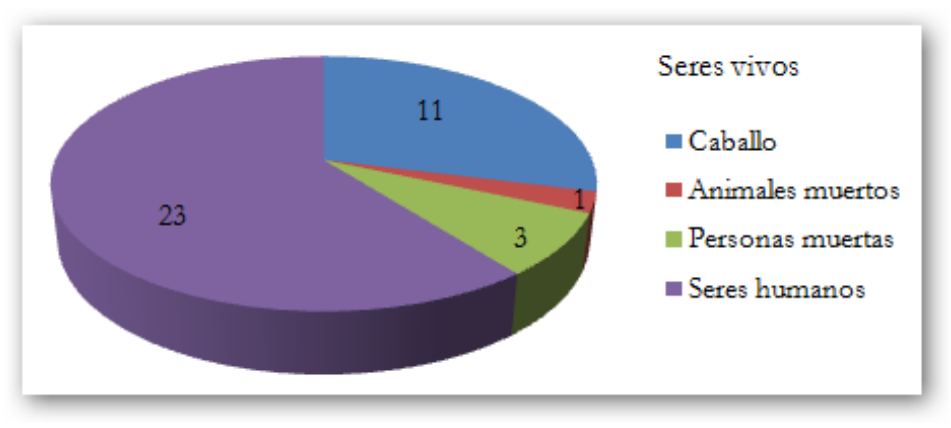

Gráfico 3. Seres vivos

En cuanto a los elementos inanimados (Gráfico 2), la llave es el objeto más representado, así como las lanzas. Destaca también la presencia de elementos que nada tienen que ver con el contexto del dibujo, como una sala de cine; además aparece una moto, un monstruo y dos emoticones. El 
gráfico 3 representa los seres vivos. Matizaremos un aspecto importante, en todos aparece representada la figura humana. Los otros tres ítems que se muestran son la representación del caballo, animales muertos-que solo aparece en un dibujo- y personas muertas, en tres dibujos.

Por lo que respecta a las características asociadas a la etapa esquemática observamos como en 13 de los 23 dibujos aparece representada la "línea base", tal y como apuntan las autoras "la estructura base del espacio está constituida por una línea horizontal o línea base sobre la que se sitúan perpendicularmente todos los elementos de la composición que según el niño están en el "suelo" " (Martínez y Gutiérrez 2001). Esta línea se ubica en la parte inferior del dibujo y en tres de nuestros dibujos se ha utilizado el borde del papel en lugar de dibujar la línea. Y únicamente en uno de ellos se ha representado el cielo con un trazo horizontal en la parte superior (Imagen 2).

Esta "línea base" tiene varias finalidades gráficas. Una de ellas es que les sirve de "apoyo" y estabilidad para los iconogramas ya definidos (Martínez y Gutiérrez, 2011). En 3 de los 13 dibujos que aparece la "línea base", se representan los personajes y las montañas en la misma línea, en cambio en los 10 restantes aparece dibujada otra "línea base" en la que se representan las montañas. Es decir, se utilizan varias líneas de base, debido a la complejidad y profundidad del espacio representado. Según Martínez y Gutiérrez la línea base (Imagen 3) es un símbolo recurrente y universal que adquiere un valor constante en este estadio.

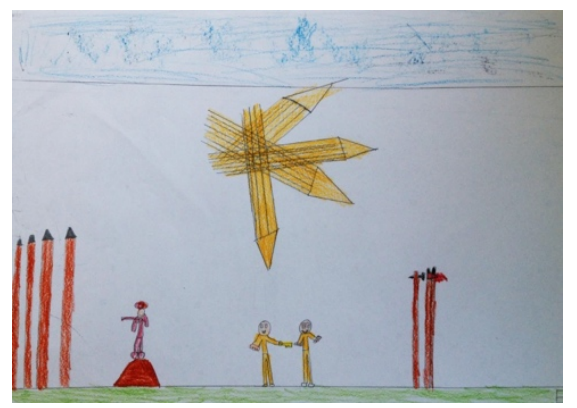

Imagen 2. Representación de la línea base (Dibujo de Nacho 8 años)

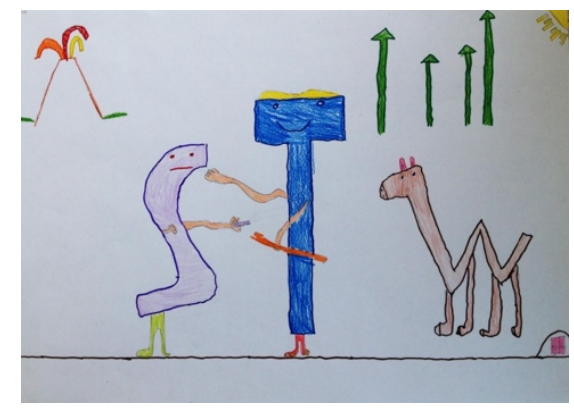

Imagen 3. Representación de la línea base (Dibujo de Manel 8 años)

Por otro lado, en todos los dibujos aparece el color, excepto en un dibujo donde solo se ha utilizado el lápiz. Además, en los dibujos donde se ha utilizado el color, se ha llevado a cabo la identificación realista con el objeto dibujado, excepto en dos dibujos donde se han pintado las montañas con dos colores diferentes al acostumbrado marrón. En uno se han pintado azules y en dos dibujos verdes (este podría tener un sentido de montañas con abundante vegetación). Es decir, utiliza el color para representar la realidad de los objetos dibujados. Por otro lado, no mezclan los colores para conseguir matices.

Otra de las características es la representación del perfil (Imagen 4). En principio, en esta etapa «el niño suele respetar siempre el plano de simetría del cuerpo que exige la frontalidad, ya que la posición de frente permite la identificación clara de los elementos esenciales» (Martínez y 
Gutiérrez, 2011) Pero esto no significa que no aparezca la representación del perfil. De hecho, en 8 de los 23 dibujos se representa la figura humana de perfil. Este esquema gráfico tiene la finalidad de expresar la acción que se está llevando a cabo en la escena y que es el gesto de los personajes centrales en la entrega de llaves. Incluso muchos han dibujado las cabezas de perfil, pero el resto del cuerpo de manera frontal. Esto se conoce como la "diversificación de los puntos de vista". Ocurre lo mismo con la imagen del caballo. Todos los animales dibujados aparecen representados de perfil. En cambio, otros escogen la solución mixta, representando las cuatro patas del animal.

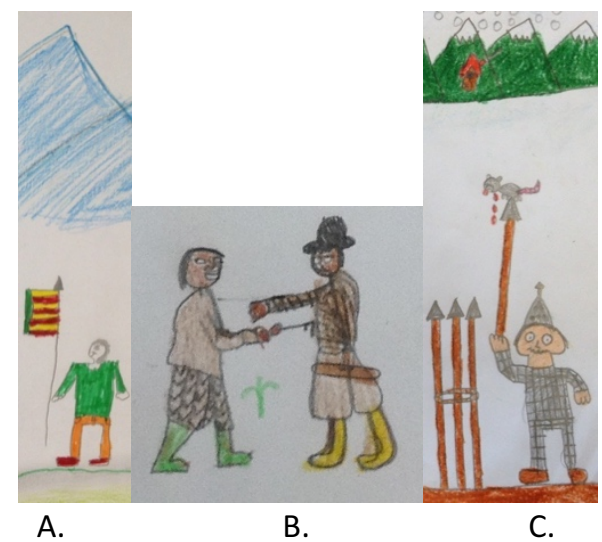

Imagen 4. Detalle de varias interpretaciones. A) Representación del perfil (Dibujo de Neus 9 años) B) Representación del perfil en la figura humana (Dibujo de Carmen V. 8 años) C) Representación del perfil en el animal (Dibujo de Julen 8 años)

Otro aspecto es la posición que adoptan los personajes centrales en los dibujos, así como la caracterización de los gestos. Analizamos, en primer lugar, la posición de los personajes centrales. El gesto de entrega de las llaves, con la postura del gobernador holandés y el gesto del brazo por parte del general genovés ha sido representado en 11 ocasiones. De hecho, 7 alumnos/as han plasmado únicamente a los dos personajes centrales obviando al resto de soldados. En cuanto a la caracterización de los gestos, tan solo en 6 dibujos se ve claramente como los gestos del bando perdedor son de tristeza y del bando ganador son de alegría.

Por último, algunas interpretaciones han sido particularmente significativas y hay que resaltar varios aspectos. Tan solo una niña ha realizado una interpretación fuera del contexto en el que se desarrolla el cuadro. Ha querido representarlo como si fuese una escena de una película cinematográfica (Imagen 5) Otra niña ha realizado su dibujo utilizando únicamente las formas geométricas, representando a todas las figuras humanas y al animal con formas circulares y las lanzas utilizando la recta. Esta representación es un claro ejemplo de la etapa esquemática que Lowenfeld define. (Imagen 6). 


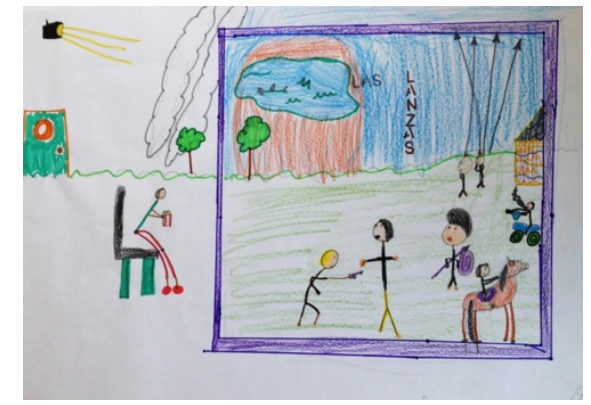

Imagen 5. Interpretación cinematográfica (Dibujo de Alexandra 8 años)

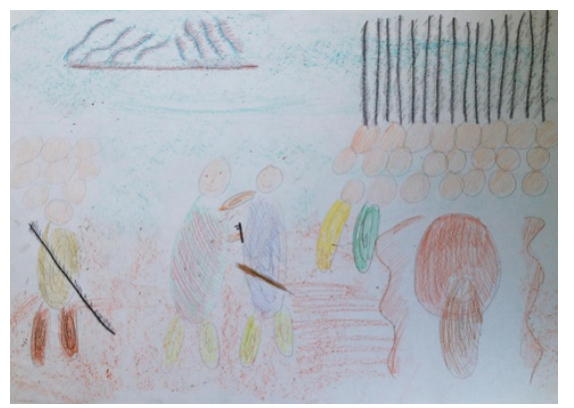

Imagen 6. Formas geométricas (Dibujo de Carmen J. 8 años)

Además localizamos otras dos interpretaciones que se han visto muy influenciadas con la parte teórica de esta investigación. Y esto se debe a la presentación que se les mostró con diversas interpretaciones de "Las Meninas". Una de ellas fue la que realizó Dalí, en la que representa todos los personajes del cuadro, humanos y animales con números. Esta forma de representación ha influenciado en dos alumnos que han resuelto la suya con letras (Imagen 7).

Es muy destacable también la representación de cuatro dibujos en los que las figuras humanas están representadas simbólicamente con líneas rectas organizadas de forma sencilla. (Imagen 8)

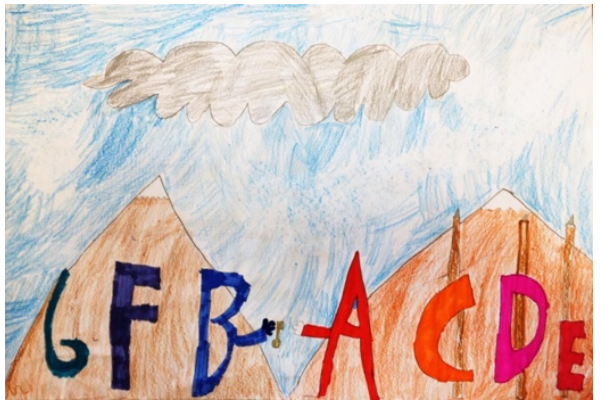

Imagen 7. Interpretación influenciada por Dalí (Dibujo de Rosa 8 años)

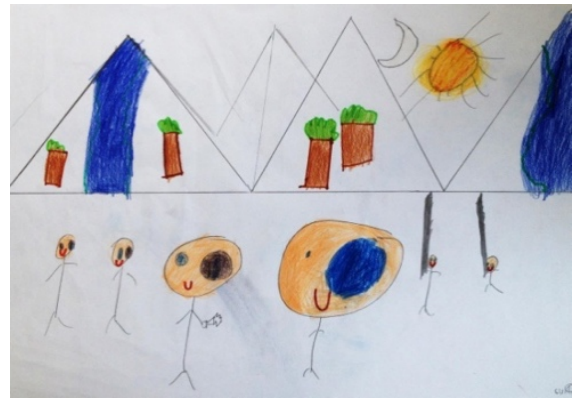

Imagen 8. Representación sencilla de la figura humana (Dibujo de Guille 8 años)

Por último, es importante destacar cómo el alumnado de 3으 Primaria ha representado el contenido de esta obra de arte. Ya matizamos en la justificación de la elección de la obra la importancia de ésta, no solo por la temática, sino por el tratamiento majestuoso y elegante que Velázquez le brinda a la escena. En 13 de los 23 dibujos se ha representado el gesto de magnanimidad y generosidad por parte de los dos personajes centrales. $Y$ es que, en todas las interpretaciones han querido representar la escena de la entrega de llaves como parte central de su composición. 


\section{Discusión y conclusiones}

Los objetivos generales, relacionados con la observación y el aprendizaje de las artes visuales para expresarse y comunicar con autonomía, han provocado una actitud de búsqueda personal y colectiva. Los resultados obtenidos de la experiencia llevada a cabo en un aula de Primaria de un centro escolar público, el CEIP Tombatossals han combinado la percepción, imaginación, indagación y sensibilidad al realizar y disfrutar de producciones artísticas. Los objetivos que nos propusimos se han conseguido en parte, puesto que, en este grupo están acostumbrados a desarrollar un modelo tradicional de enseñanza en el aula y nuestro proyecto radicaba en la observación y la experimentación. Por tanto, intencionadamente hemos propuesto un nuevo método de trabajo con el que hemos conseguido implicar al alumnado de una manera diferente. Introduciendo, por un lado, el estudio de la obra de un pintor relevante desde el que analizar sus principales características y de este modo, provocar su interés por el arte.

Por otro lado, hemos comprobado con la revisión de las características de los ejercicios que muchos de ellos representan con las estrategias que caracterizan a la etapa esquemática puesto que ésta es una representación que no incluye experiencias intencionales concretas, es decir, que se limita a enunciar el objeto o sujeto con el esquema conseguido finalmente para este concepto, Lowenfeld y Lambert (1980). Nos parece importante recordar que el objetivo de este trabajo no era enseñarles a dibujar. El fin era poner en práctica una estrategia para que el alumnado de estas edades se enfrentase a un papel en blanco e interpretase un cuadro. A través de estas interpretaciones, descritas en el apartado de resultados, hemos comprobado, que la gran mayoría de los niños/as han plasmado las características que van asociadas a la etapa gráfica esquemática. En referencia al dibujo, la disposición corporal de los personajes tiene relación con lo que se puede ver en la obra pictórica pues diferencia las características físicas del sexo masculino y femenino; además de manejar la distribución espacial mediante la línea del horizonte y la línea de base, así como, el aumento o disminución de tamaño para indicar cercanía o lejanía. En cuanto al color no se utiliza como símbolo de un estado de ánimo, sino que su uso es para identificar el objeto representando la realidad. En algunos casos observamos el poco interés que tienen al realizar el dibujo. Puesto que, unos apenas representan elementos de la naturaleza y otros la figura humana no tiene ningún tipo de proporción y está muy simplificada. Tenemos que recordar que en estas edades (entre los 8-9 años) algunos niños abandonan su satisfacción por dibujar, ya que se sienten frustrados y pierden la motivación influenciados sobre todo por los pocos estímulos escolares y familiares. De hecho, ellos mismos nos decían que no sabían dibujar y que no se sentían cómodos haciéndolo. Por lo que, no les insistíamos y dibujaban cómo querían y podían. Realmente 
consideramos que es una lástima que, desde la escuela, y sobre todo desde la asignatura de Plástica, no se promueva ninguna actividad relacionada con la didáctica del dibujo. Pero para ello, tenemos que plantearnos antes una pregunta ¿cuántos docentes tienen una formación relacionada con las artes plásticas? Hay que decir que el sistema educativo ha ido acomodando al profesorado, que a pesar de los beneficios que esta materia aporta, como hemos podido comprobar con esta experiencia, pocos son los que se aventuran con iniciativas innovadoras.

Esta investigación nos ha proporcionado una serie de evidencias que comentamos a continuación. En primer lugar cabría destacar la carencia de la presencia de la Historia del Arte en las aulas de Primaria. El lenguaje visual, como tal, tiene sus propios códigos y no podemos ser ajenos a ellos pues vivimos en un mundo lleno de imágenes. Por tanto, parece lógico y fundamental iniciar en la escuela ya en un aprendizaje basado en la decodificación de estos mensajes visuales pero no sólo del presente sino también del pasado. Tal y como dice el autor «continúa privilegiando el lenguaje verbal, y colocando en una posición subordinada el visual» (Socias, 1996:11). Por tanto, es necesario educar la percepción visual y artística para que de este modo, nuestro alumnado aprenda a observar, interpretar y describir una obra de arte. Pero este proceso tiene una larga duración durante toda su etapa educativa, por lo que es necesario introducirlo desde las edades más tempranas, ya que el aprendizaje se realiza de forma gradual.

Sin embargo, actualmente en los contenidos de Educación Primaria hay escasas referencias a la evolución del arte a lo largo de la historia. Por tanto, el alumnado llega, muy posiblemente, a la etapa de educación secundaria obligatoria sin tener unos conocimientos básicos sobre la evolución del arte como expresión artística de las sociedades a lo largo del tiempo. Si bien es cierto, que en la asignatura de Conocimiento del Medio se hace referencia a ciertos aspectos de historia del arte, desde nuestro punto de vista, el enfoque que se le da no es el adecuado. Nuestra propuesta sería conocer la importancia que tiene el arte, en sí, mostrando la evolución de los grupos sociales que, desde los clanes prehistóricos evolucionan hasta la sociedad actual. Así pues, realizar un recorrido por las primeras sociedades estatales, la creación de grandes imperios como el Romano, la conformación de la Europa Medieval, la aparición de los Estados Nación y la irrupción de la sociedad capitalista y de la sociedad de masas. Pero, ¿cómo concretizar estas ideas con la asignatura de Plástica? El docente deberá contextualizar la obra de arte, esto es, relacionándola con la sociedad de la época y los principales hechos históricos. Un ejemplo claro es este trabajo sobre el cuadro de Velázquez "La Rendición de Breda", conocido popularmente como "Las Lanzas". En la primera sesión realizamos una exposición teórica con el contexto en el cual se enmarca la obra de arte, explicando al alumnado dónde y cuándo se ubica. Es importante que conozcan cómo, en este caso, el poder del monarca se refleja en la representación de esta obra, ya que Spínola recibe las llaves de la ciudad. Al mismo tiempo sensibilizamos en la necesidad de conservar 
el patrimonio cultural y artístico no sólo de nuestra sociedad sino de la humanidad en general, ya que el desconocimiento de la evolución del arte es sinónimo del desconocimiento de la evolución de las sociedades. Claro está, desconocer el pasado de la humanidad no sólo supone desconocer los hechos positivos para el conjunto de los seres humanos, sino también los abusos del poder. Con esto, no queremos más que significar que la práctica artística acompañada del conocimiento de la historia debería ser inseparable.

Vivimos en una sociedad marcada por el sistema productivo, fundamentado en producir para obtener unos beneficios. El sistema educativo no fomenta el desarrollo del potencial creativo del alumnado, tampoco su inventiva o la experimentación personal, ni tan siquiera la observación. Estamos generando una sociedad carente de algo fundamental y esencial para el desarrollo de una sociedad democrática, la capacidad de pensar, tanto de manera individual como colectiva. Es por esto que, tendríamos que reflexionar sobre una pregunta que muchos estudiosos del área de la Educación Artística se hacen: ¿qué está ocurriendo en la asignatura de Plástica en los centros educativos? Es evidente que en muchas aulas esta asignatura es la gran olvidada, ya que no existe una programación didáctica de forma explícita. La gran mayoría opta por realizar, en sus clases, fichas repetitivas para colorear. Con la puesta en práctica de este proyecto en el aula de tercero de Primaria del CEIP Tombatossals he podido comprobar cómo el alumnado ha mostrado buena predisposición participando activamente en la propuesta. De hecho, al principio mostraban sus inquietudes y preocupaciones pero hemos de recordar que están acostumbrados a colorear fichas y no a elaborar dibujos propios. Acostumbrados a utilizar lápices de colores, de madera o de plástico, y cuando quieren utilizar otro tipo de material, ya sea rotuladores o ceras blandas, necesitan la aprobación del docente. Al estar siempre condicionados por el material que deben y no deben utilizar les limitamos la libertad creativa, mermando su capacidad de decisión. En el aula, disponen de material diverso: pinturas, rotuladores, ceras blandas, bloc de dibujo, pinceles, reglas, entre otros, pero no se les ofrece la oportunidad de escoger libremente. Dadas estas circunstancias, en la aplicación didáctica de este proyecto, nos limitamos a explicarles en qué consistía interpretar una obra pictórica pero en ningún momento el material que debían utilizar. Durante la ejecución de la interpretación al alumnado le surgían dudas sobre la utilización de un determinado material, por ejemplo, rotuladores o ceras, es entonces cuando les proporcionábamos la libertad para decidir.

La limitación de escoger entre varias alternativas tiene mucha relación con las consecuencias educativas que tiene el modelo tradicional de enseñanza versus el modelo de autoexpresión creativa que explicó Lowenfeld en los años 60. Está demostrado que utilizar para el aprendizaje de la educación en las artes visuales únicamente el modelo tradicional basado en la imitación tiene consecuencias negativas en el alumnado por lo que consideramos que debería aplicarse como complemento a otros 
modelos. Puesto que las consecuencias de ir indicando constantemente lo que deben hacer podrían frustrar y limitar al no poder inventar sus propias formas, expresar sus ideas, sensaciones y sentimientos dada la dependencia que surge al adherirse a formas establecidas, como por ejemplo colorear dibujos. En cambio, la libertad de elección del material ya promueve la autonomía de acuerdo con el nivel personal del niño/a, así como un pensamiento independiente. En nuestro proyecto para fomentar esta exploración nos hemos apoyado en el modelo de autoexpresión. Además de seguir unas pautas metodológicas para llevar a cabo la interpretación. La primera y fundamental ha sido la temática del dibujo que debían realizar y explicarles que tenían que hacer una interpretación del cuadro en cuestión después de observar y analizarlo. Por tanto, todos/as han podido plasmar sus ideas y sensaciones bajo una temática común, el cuadro de "Las Lanzas".

\section{Bibliografía}

ÁvILA, R.M. (2003): «Los maestros y los contenidos histórico-artísticos. Una experiencia de formación inicial en relación con la selección e interpretación de obras de arte para la Educación Primaria», Enseñanza de las Ciencias Sociales, 2, ICE de la Universidad de Barcelona e ICE de la Universidad Autónoma de Barcelona, Barcelona.

CORTón, M.T. (1998): "La lectura de la obra de arte en la Educación Primaria», Tendencias Pedagógicas, 1, Departamento de Didáctica y Teoría de la Educación de la Universidad Autónoma de Madrid, Madrid.

EQUIPO DIDART (2000): «El arte como argumento educativo», en HERNÁNDEZ, M. y M. SÁNCHEZ (ed.): Educación artística y arte infantil. Fundamentos, Madrid.

GARDNeR, H. (1994): Educación artística y desarrollo humano, Paidós Educador, Barcelona.

GENET, R. y X. Molinet (2014): El color del aprendizaje de los maestros. En las actas de la 2 a Conferencia sobre Investigación basada en las Artes e Investigación Artística del 27 al 30 de enero de 2014. Granada.

Marín-VIAdel, R. (Coord.) (2003): Didáctica de la Educación Artística para Primaria, Pearson Educación, Madrid.

MARTínez, L. y R. GutiéRREz (2011): Las artes plásticas y su función en la escuela, Ediciones Aljibe, Málaga.

MedinA, Mạ. D. (2006): "Expresión plástica y su didáctica», Manuales docentes de Educación Primaria, no 11, Universidad de Las Palmas de Gran Canaria. 
Mendioroz-lacambra, A. M. (2013): «Empleo de la Historia del Arte para la adquisición de nociones estructurantes del área de Conocimiento del Entorno en Educación Infantil: espacio y tiempo", Arte, Individuo y Sociedad, 25(3), Servicio de Publicaciones de la Universidad Complutense de Madrid, Madrid.

Ministerio de EDUCACIÓN Y CIENCIA (1992): Primsrie. Área de Conocimiento del Medio, Madrid: Secretaría de Estado de Educación.

PÉREZ, R.G. (2012): "Educación Artística y Comunicación del Patrimonio», Arte, Individuo y Sociedad, 24(2), Servicio de Publicaciones de la Universidad Complutense de Madrid, Madrid.

Portús, J. (2012): Guía de la colección. Velázquez, Museo Nacional del Prado, Madrid.

TORRES, M. y R. JUANOLA (1998 a): Dibuixar: mirar i pensar. Consideracions sobre educació artística, Rosa Sensat, Barcelona.

- (1998 b): Una Manera d'ensenyar arts plàstiques: 140 exercicis per a educació infantil i primària, Rosa Sensat, Barcelona.

Valenciano, J.L. (2006): Educación Plástica, Gobierno de Navarra. Departamento de Educación, Pamplona.

WILSON, B. y otros (2004): La enseñanza del dibujo a partir del arte, Ediciones Paidós, Barcelona.

\section{Anexo 1}

En el presente anexo acompañamos las 23 interpretaciones realizadas por el alumnado de 3을 Educación Primaria del CEIP Tombatossals.

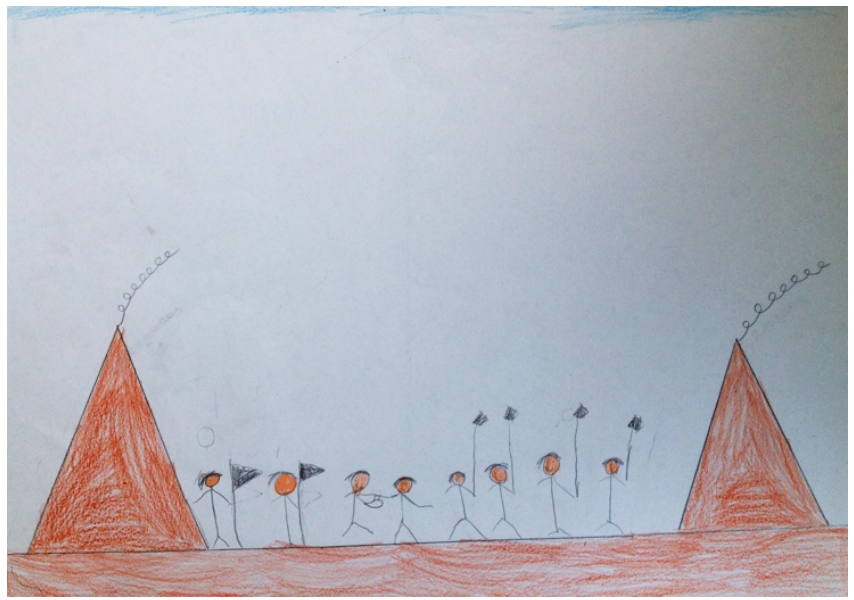

Imagen 1. Ainhoa (8 años) 

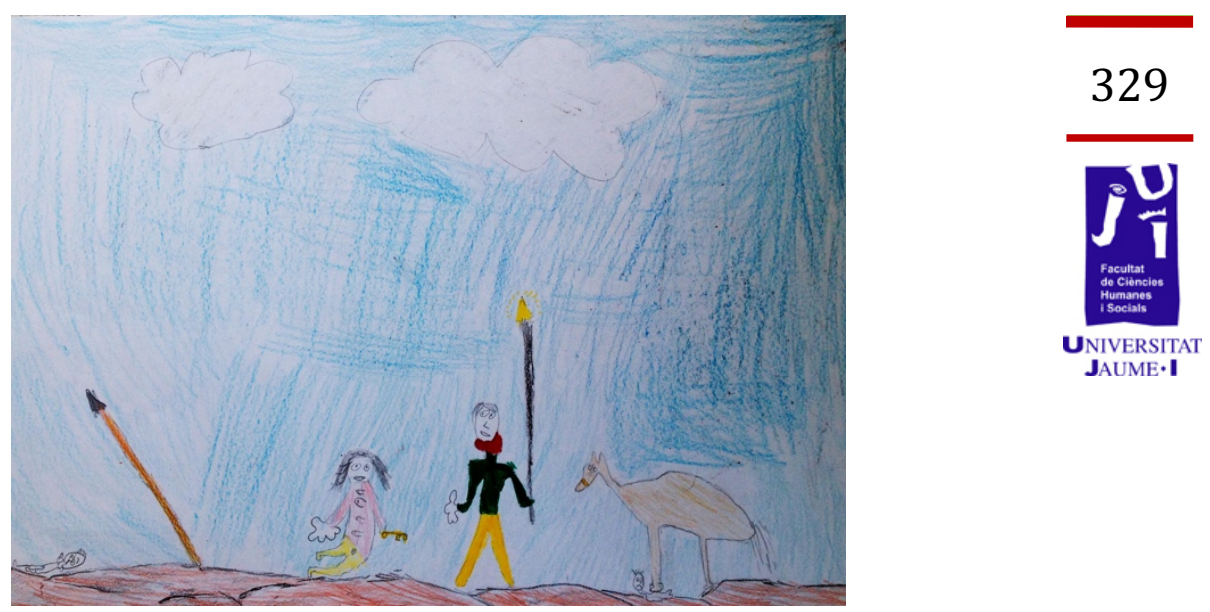

Imagen 2. Alex (8 años)

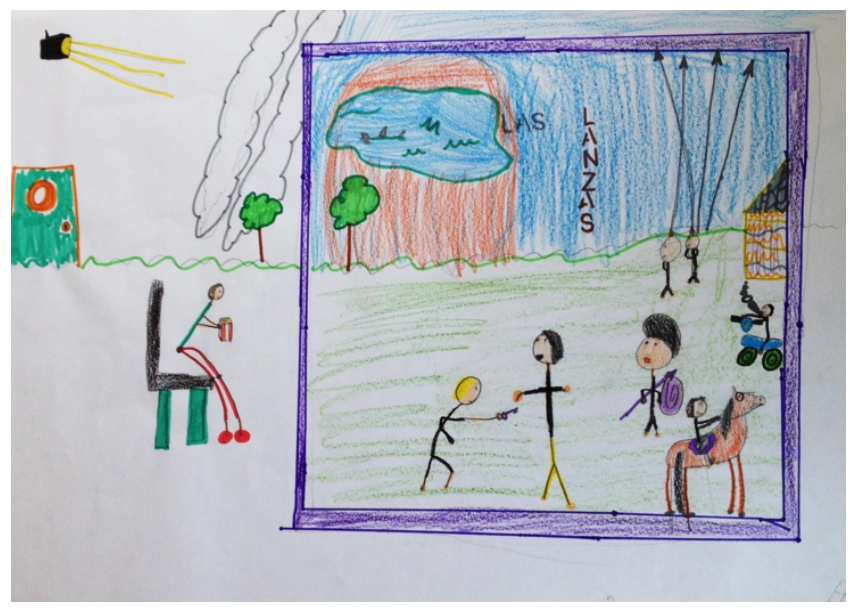

Imagen 3. Alexandra (8 años)

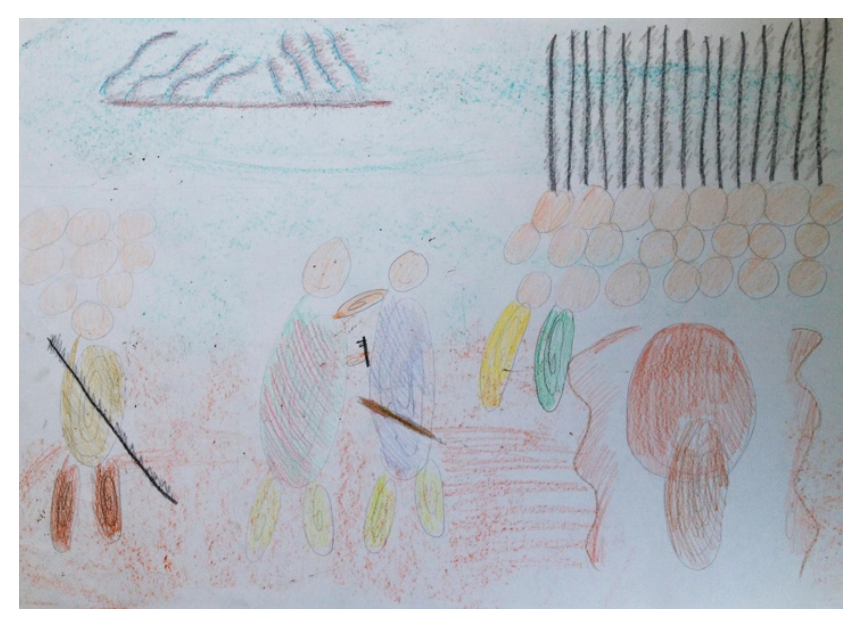

Imagen 4. Carmen J. (8 años) 


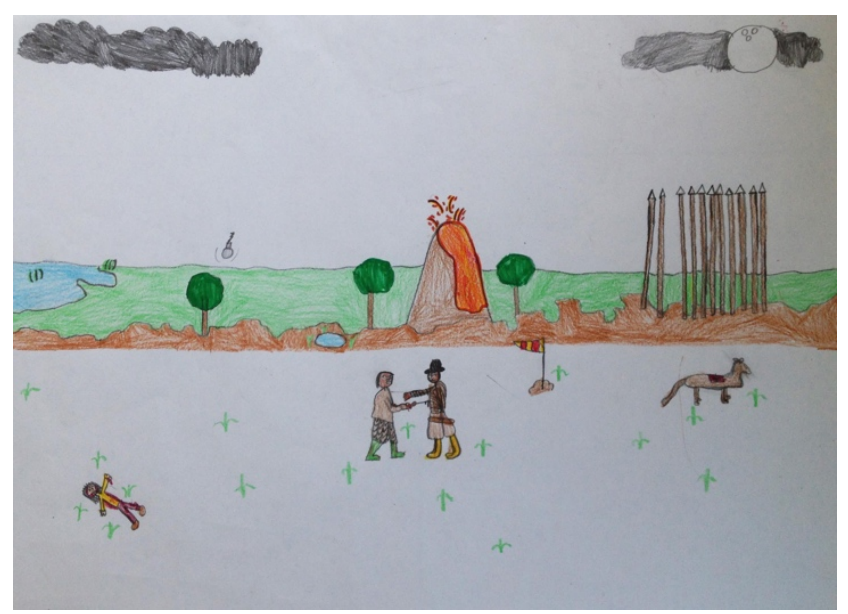

Imagen 5. Carmen V. (8 años)

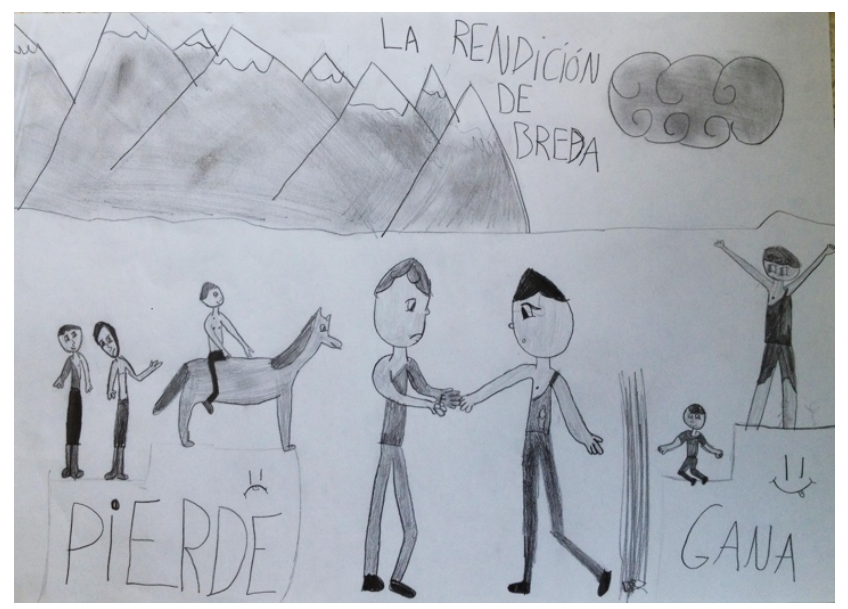

Imagen 6. Cristina (8 años)

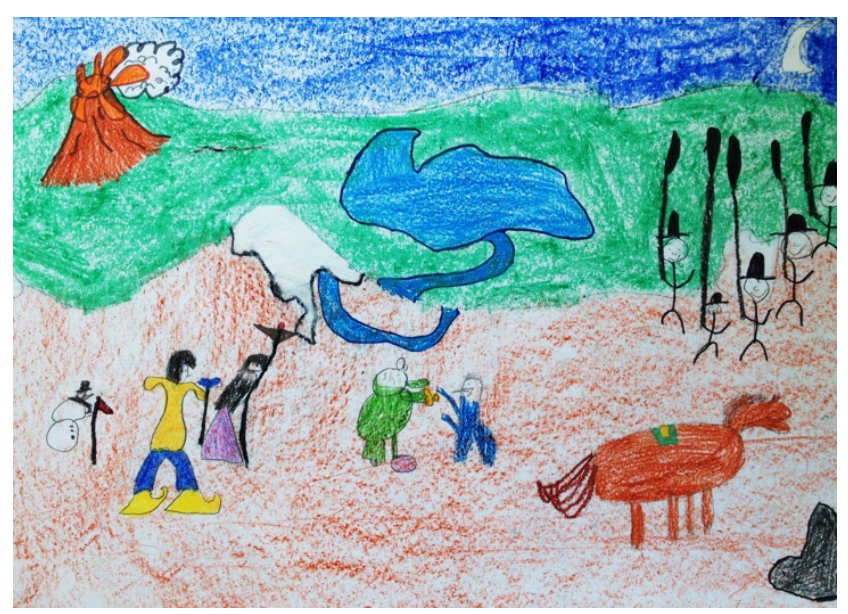

Imagen 7. Eric (8 años) 

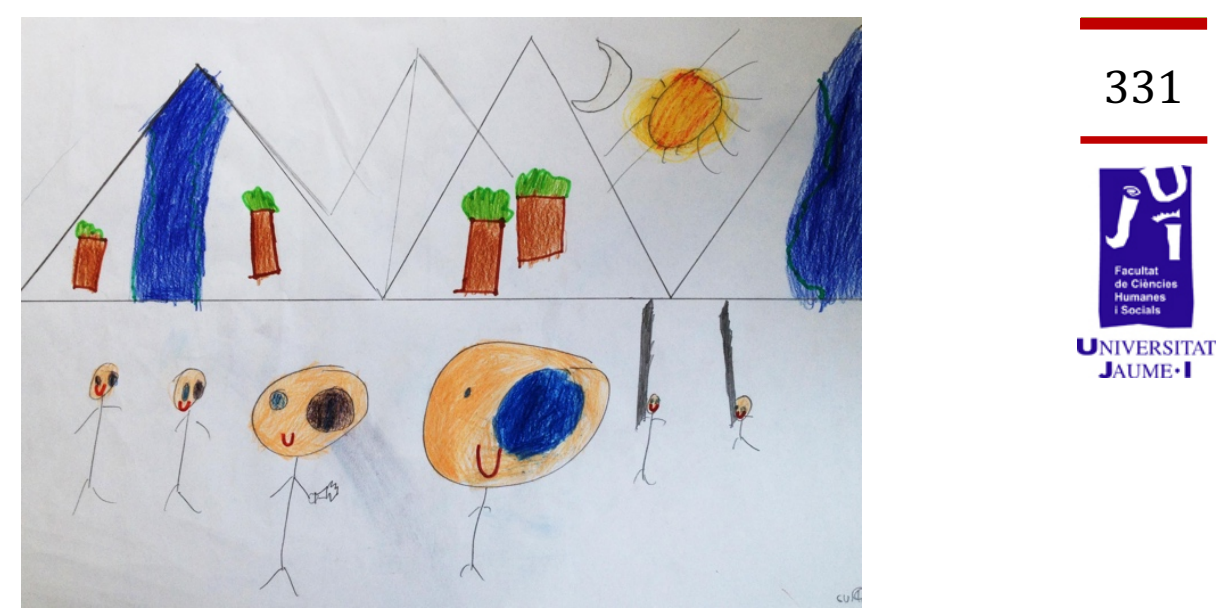

Imagen 8. Guille (8 años)

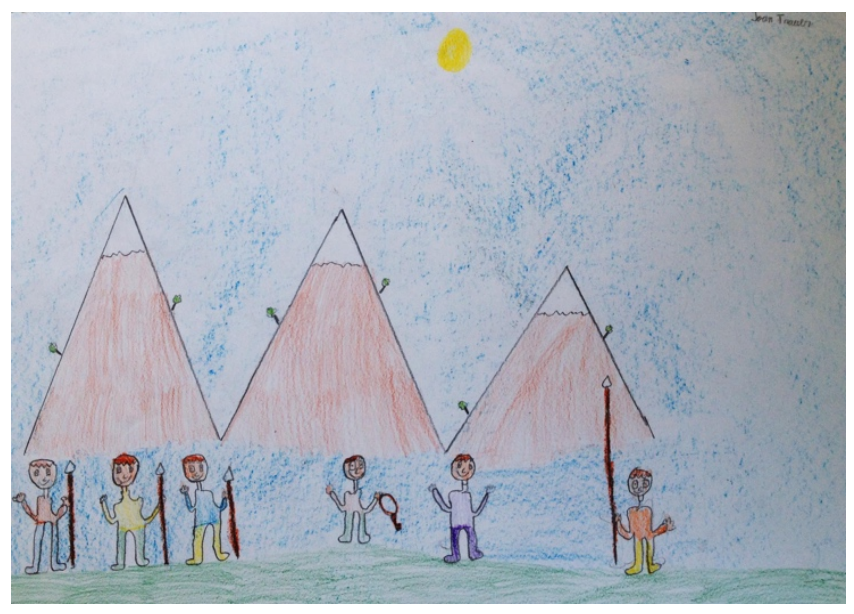

Imagen 9. Joan (8 años)

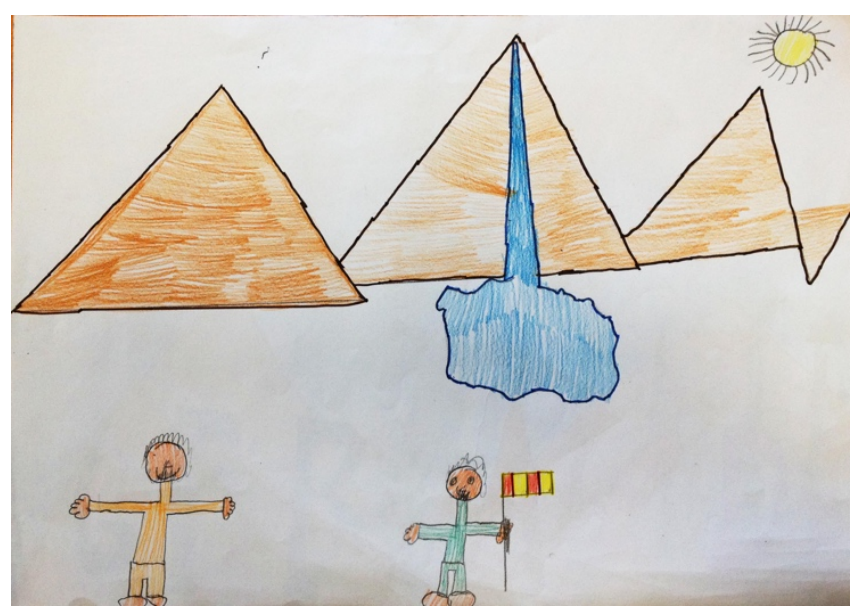

Imagen 10. Juanjo (8 años) 


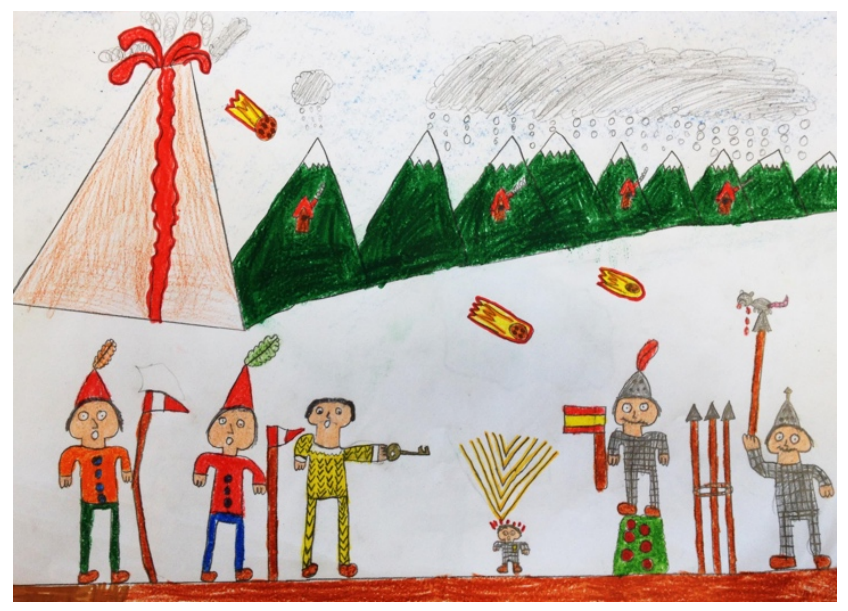

Imagen 11. Julen (8 años)

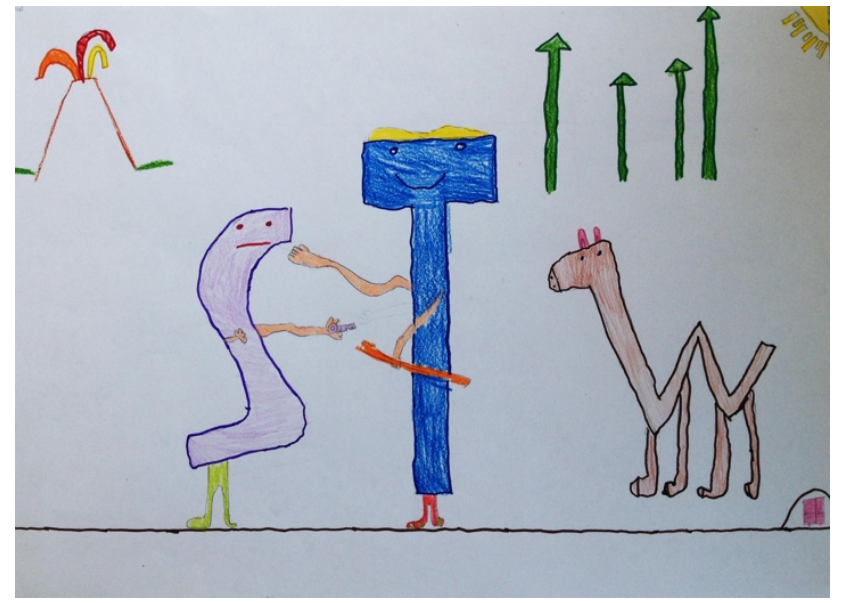

Imagen 12. Manel (8 años)

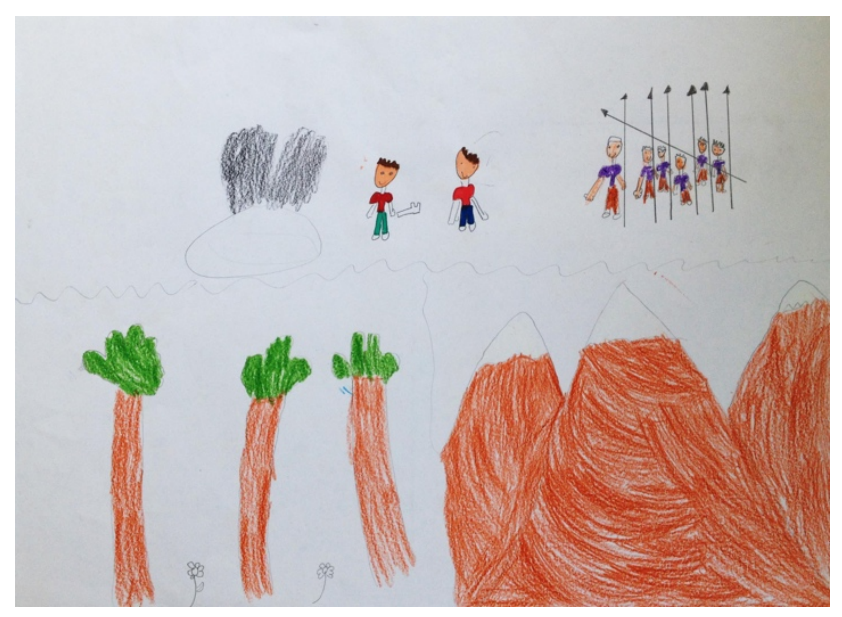

Imagen 13. Mar (8 años) 

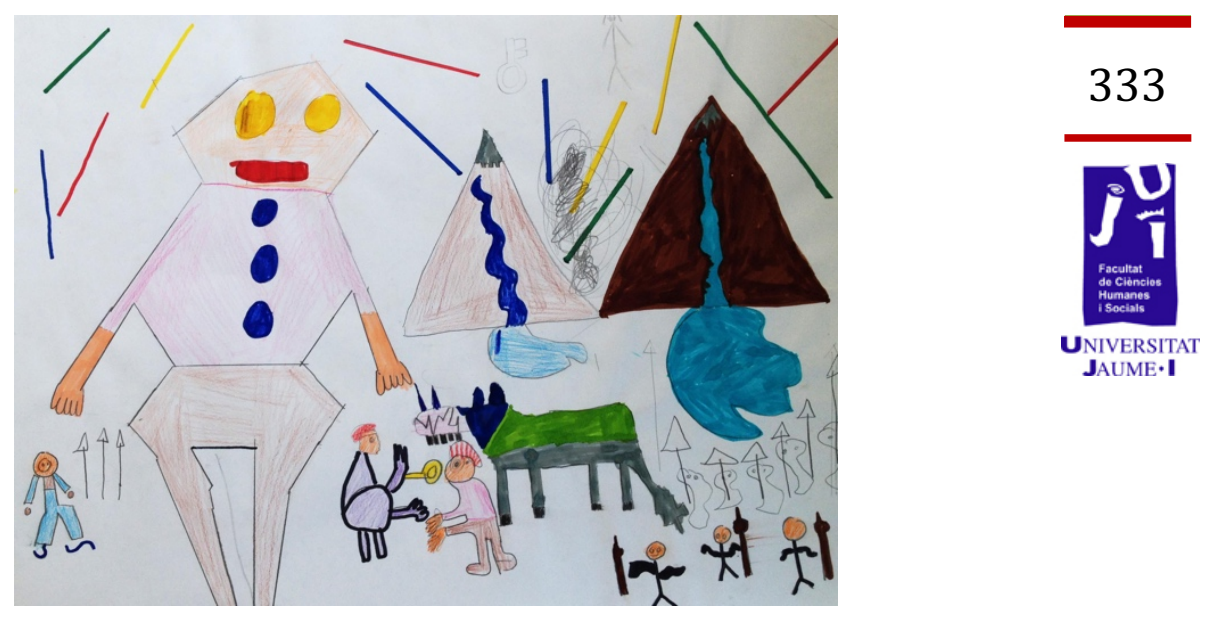

Imagen 14. Mario B. (8 años)

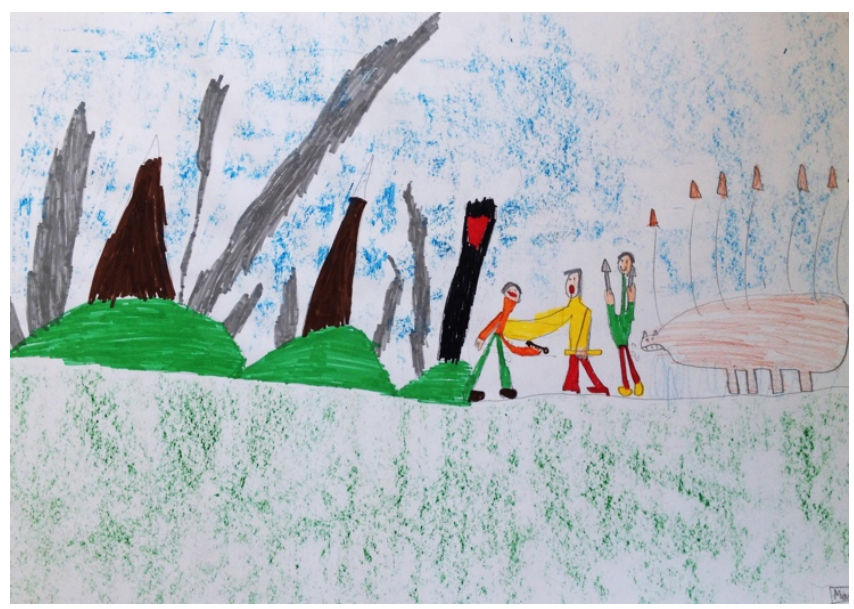

Imagen 15. Mario T. (8 años)

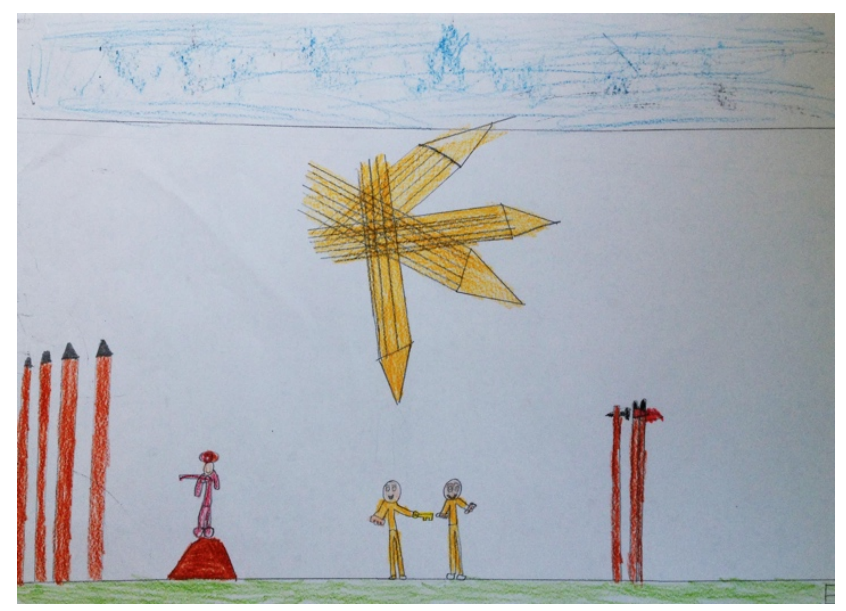

Imagen 16. Nacho (8 años) 


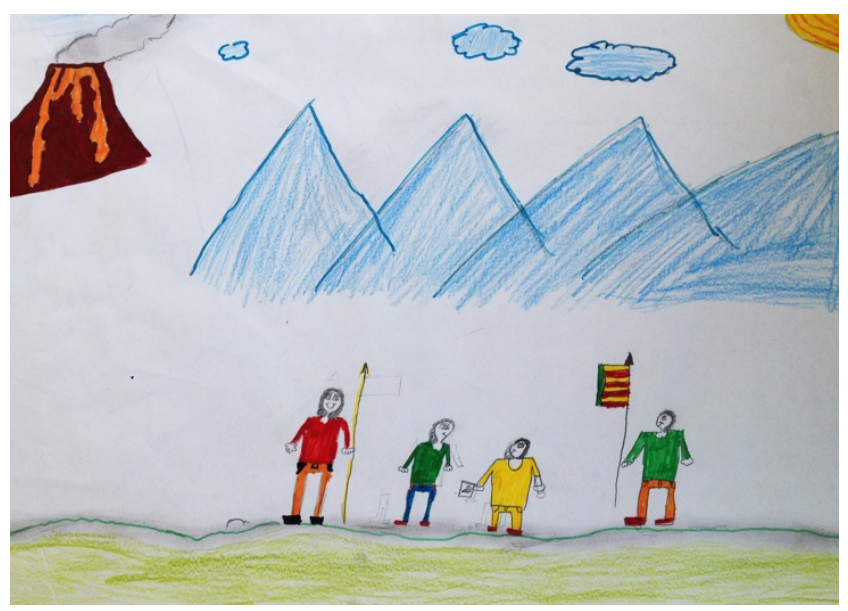

Imagen 17. Neus (9 años)

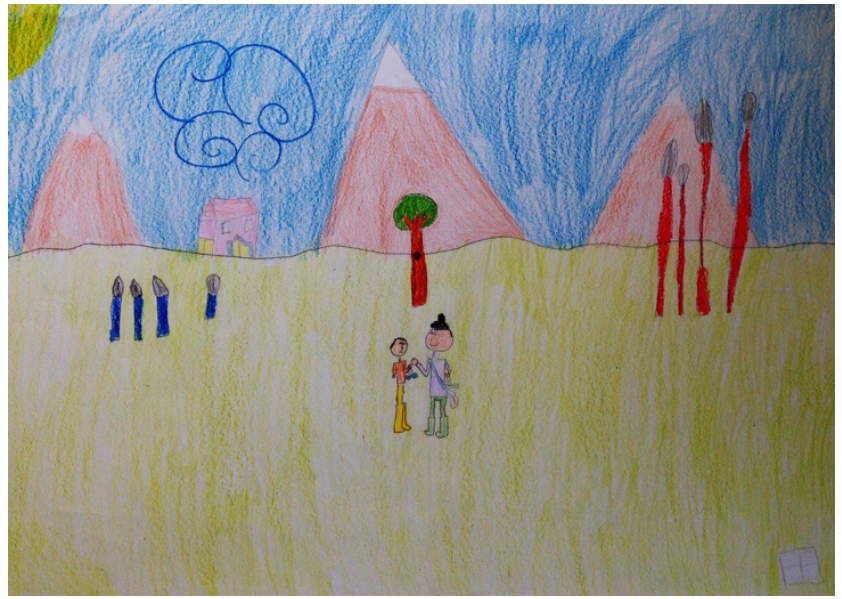

Imagen 18. Nuria N. (8 años)

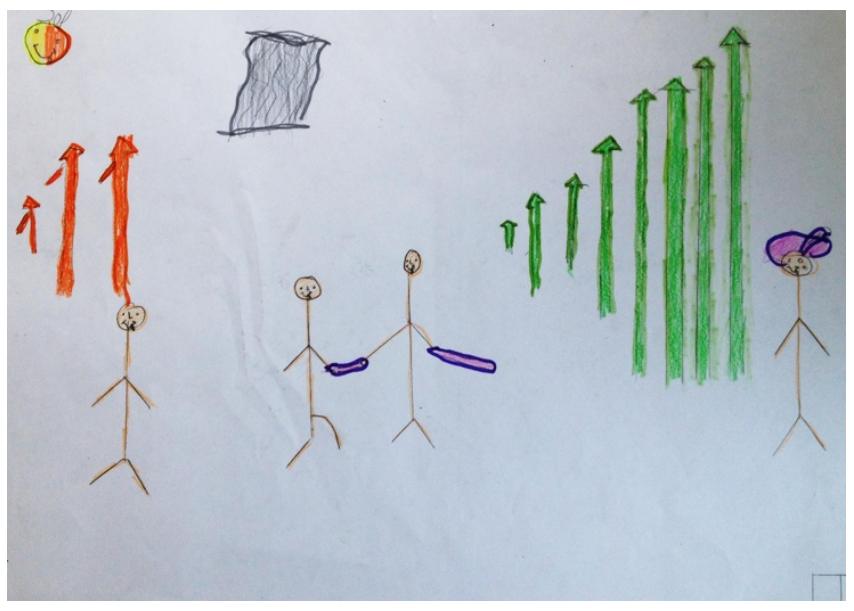

Imagen 19. Nuria R. (8 años) 

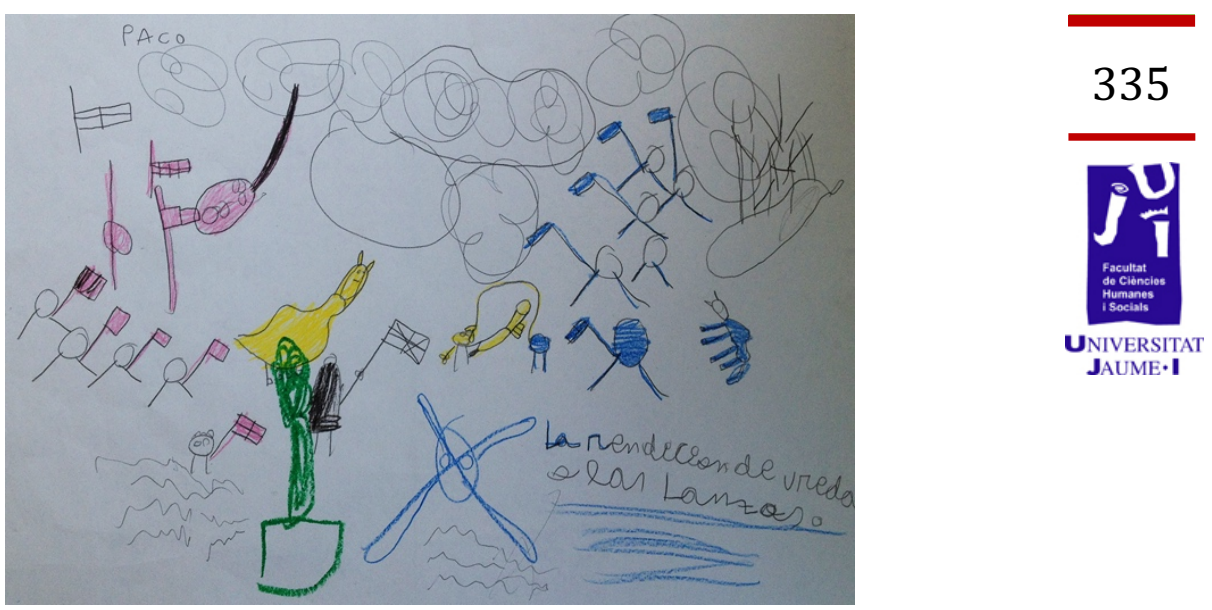

Imagen 20. Paco (8 años)

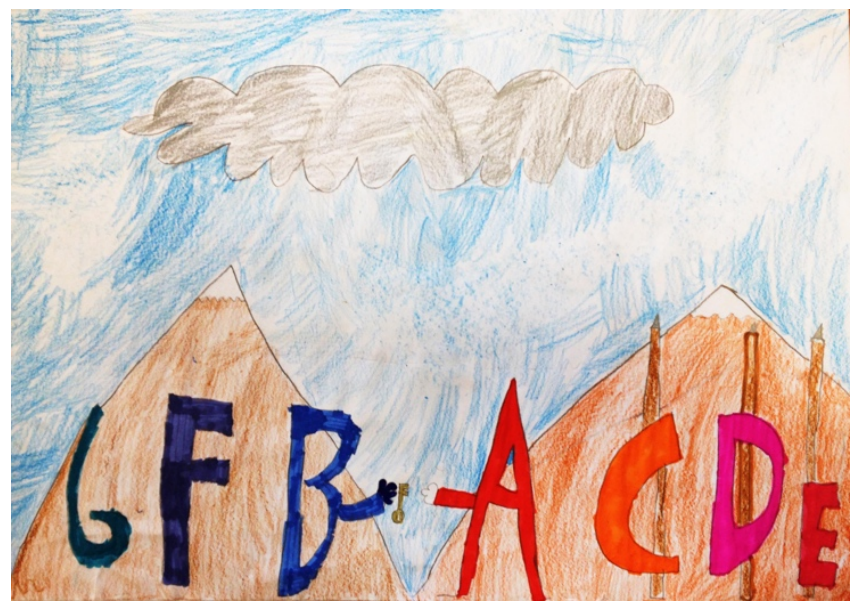

Imagen 21. Rosa (8 años)

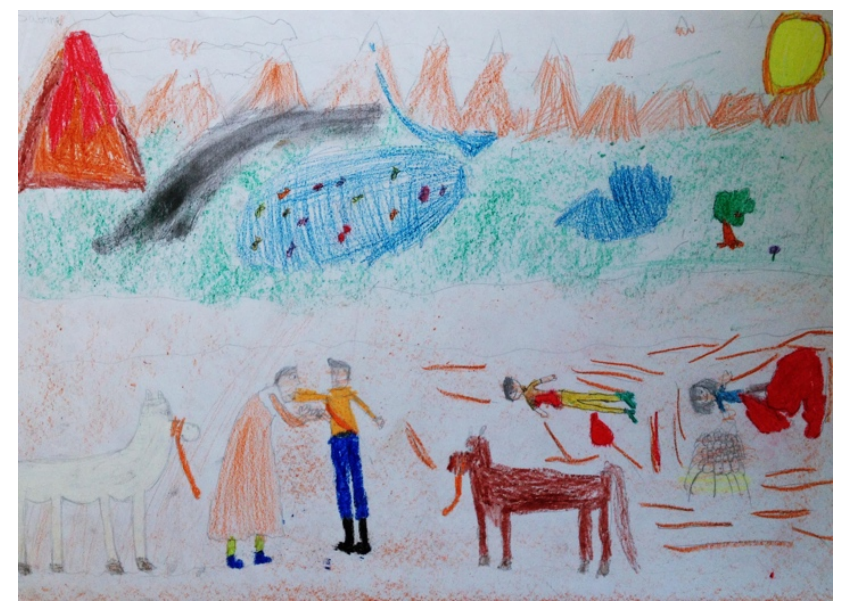

Imagen 22. Sabrine (8 años) 
FÒRUM DE RECERCA
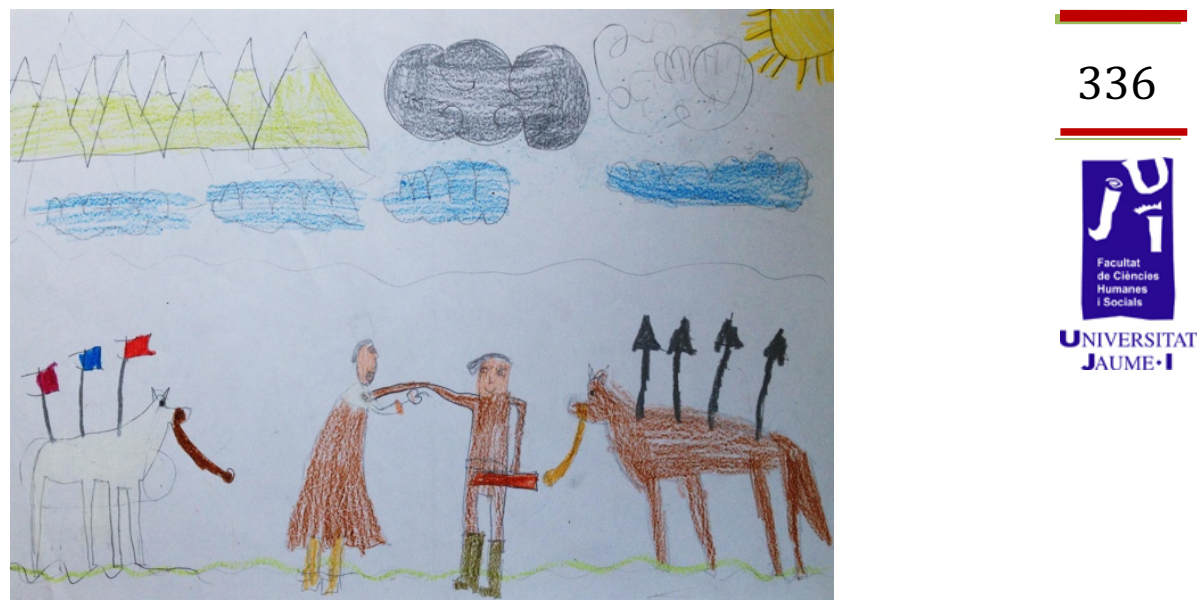

Imagen 23. Sole (10 años) 